(Invited Paper - Third International Conference on Ion Implantation: Equipment and Techniques - July 8-11, 1980 - Canada)

$$
\text { SONF- do0738-1 }
$$

\title{
ASPECTS OF THE PHYSICS, CHEMISTRY, AND TECHNOLOGY OF \\ HIGH INTENSITY HEAVY ION SOURCES
}

$$
\text { G. D. ALTON }
$$

Oak Ridge National Laboratory

Oak Ridge. Tennessee 37830, U.S.A.

\section{MASTER}

\section{ABSTRACT}

Particular emphasis is placed on the technology of plasma discharge ion sources which utilize solid elemental or molecular compounds to produce vapor for the ionization process. A brief discussion is made of the elementary concepts underlying the formation and extraction of ion beams from plasma discharge sources. A limited review of low charge state positive ion sources suitable for accelerator use is also given.
\end{abstract}

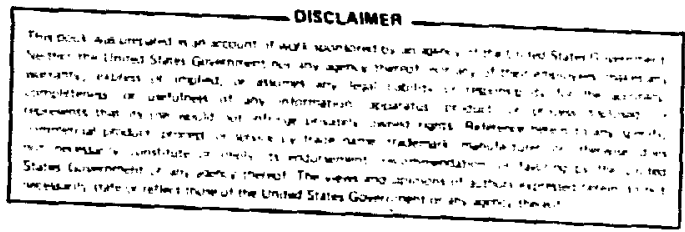

By acceplance of inis article. the publisher or recitient acnnowiedges :he U.S. Government: right to rotain a noit - exrlusive, rovalty - irra? lie ence 11 and to any cooyright covering the article.

\footnotetext{
* Research sponsored by the Department of Energy, Division of Basic Energy Sciences under Contract No. W-7405-eng-26 with Union Carbide Corporation.
} 
1. Introduction

The numbers and varieties of heavy ion sources used in conjunction with the various types of acceleration systems has rapidly increased in recent years due to the interest in heavy ion beams for industrial production applications, basic and applied scientific research, as well as their traditional use in electromagnetic isotopes separation processes. The diversity of beam requirements and the widely differing chemical and physical properties of the materials necessary for the generation of the ion beams has prevented, to date, the design of an ideal universal positive ion source. However, ion sources exist today which are capable of producing low charge positive ion beams of every element in the periodic chart with sufficient intensities to meet the requirements of most users.

Ions may be produced from neutral vapors by the interaction of photons, electrons, ions, and static or high frequency electric fields with atoms and molecules which make up the vapor or by surface ionization phenomena. The predominant methad for producing a highly ionized medium from which intense beams of positive ions can be extracted is by creation of magnetically directed or confined electrical (plasma) discharge which is supported wholly or in part by a gaseous vapor which contains the material of interest. This method is universal in that any ion species can be created and therefore is the method most often used in the design of versatile heavy ion sources for the production of intense ion beams. In this report, emphasis will primarily be placed on the discussion of the physics, chemistry and technology associated with plasma discharge sources because of their universal character. Other methods of ion production which have a more limited ion generation range, such as surface ionization sources will receive less attention. 
Ion sources are indepensible to the operation of accelerators and have been used in such programs for many years. The ion source not only produces the ion beam upon which the acceleration process relies but, more often than not, is the most troublesome component in the acceleration system. In fact, the degree of success of a particular accelerator related program depends substantially on the performance of its ion sources in terns of intensity, stability, and lifetime. For example, lifetime limitations in plasma discharge sources are largely due to the corrosive and errosive processes necessary for ion generation. Many universal heavy ion sources are required to operate at elevated temperatures with corrosive and reactive vapars which may severely limit the lifetimes of the materials of construction. By the very nature of the plasma generation process, cathode lifetimes in arc plasma discharge sources are limited, principally by physical sputtering and in many cases, by a combination of physical sputtering and chemical reaction processes. Source performance, in terms of intensity and stability, may be affected by such factors as choice of feed material, material feed rates, mode of source operation, and skill of the operator.

Due to the indepensable nature of the ion sources to accelerator related programs, and the technological complexities associated with the generation of adequate intensities of a wide variety of ion species with diverse chemical and physical properties, ion sources and their technologies have been the subject of several review articles. They have aiso been included as a principal subject in several ion source or ion beam related conferences, and the subject of very large numbers of publications on specific sources in the open literature. An early review of the subject was made by Von Ardenne ${ }^{1}$ ) 
which principally describes the duoplasmatron source. A review article by Gabovich ${ }^{2}$ ) is dedicated to more universal, high temperature heavy ion sources. Gabovich also has authored a book ${ }^{3}$ ) solely devoted to the subject of the physics and technology of plasma type ion sources. A discussion of the chemistry and technology of heavy ion sources was made by Freeman and Sidenius ${ }^{4}$ ). Dearnaley et ai. $\left.{ }^{5}\right)$ devote an extensive and rather comprehensive review article to the subject of heavy ion sources used in ion implantation processes. Wilson and Brewer included an excensive section to heavy ion sources in their book on "Ion Becms with Applications to Ion Implantation" negative ion sources suitable for accelerator use was made by Alton ${ }^{7}$ ) which includes, among other subjects, a discussion of the basic physical processes involved in the formation and extraction of ion beams from plasma ion sources and methods of vapor transport. Green has written a detailed article on the subject of high intensity ion sources in which emphasis is placed on the physics and ion optics of these sources $\left.{ }^{8}\right)$. A general review article by jidenius includes a large number of review references on the subject and describes the principles of operation of several types of sources $\left.{ }^{9}\right)$. Severai conference proceedings exclusively devoted to the subject have been published ${ }^{10-15}$ ) and other conference proceedings, such as those concerning electromagnetic isotope separation processes ${ }^{16-20}$ ), ion implantation ${ }^{21}$ ), ion bombardment of solid surfaces ${ }^{22}$ ), and ion beam related conferences ${ }^{23}$ ) contain articles on the subject. The reader is referred to these and the references contained within for specific information on the emission properties and constructional details of specific heavy ion sources.

In this report, emphasis will be placed on the physics, chemistry, and technoiogical aspects of high intensity, low charge state positive ion sources suitable for accelerator use. Most of the material will deal with plasma discharge sources because of their versatility of species generation 
capabilities. The large number of ion sources, which are being used with the many types of accelerators in existence, prevent a comprehensive survey of the ion sources and their technology, therefore, an effort will be made to concentrate on ion sources which have a capability of producing a variety of low charge state positive heavy ion beams.

\section{Plasma Discharge Sources}

\subsection{VAPOR TRANSPORT METHODS}

The technology for producing copious intensities of every element in the periodic chart exists today and has been developed principally by electromagnetic isotopes separation groups. The success of the isotope separation process depends heavily on the reliability of the ion sources used. The sources must operate steadily for long periods of time at elevated temperatures with a wide variety of corrosive and reactive materials. Invaluable information on the techniques and desired feed materials has been complied as a result of many years experience by isotopes separations groups ${ }^{24-26}$ ).

Plasma discharge ion sources have varying degrees of species generation capabilities depending on whether or not they are equipped with an oven for solid material vaporization. Duoplasmatron, radio frequency, and cold cathode Penning type sources are designed for gaseous and high vapor pressure liquid feed materials. However, with certain modifications these sources have been successful in extending the range of icn species capabilities by incorporating sputter probes or ovens.

More universal type sources, such as the Scandinavian ${ }^{27}$, circular aperture source and the calutrun ${ }^{29}$ ), magnetron ${ }^{30,31}$ ), and Freeman $^{32}$ ) slit aperture sources, and their several variations have controllable temperature capabilities of $300^{\circ} \leq T \leq 1100^{\circ} \mathrm{C}$. These sources 
can also be equipped with sputter probes for producing beams of the Pt-Pd groups of elements.

The hollow cathode source developed by Sidenius ${ }^{28}$ ) can also be described as a universal ion source and has a much broader temperature range $\left(200^{\circ} \mathrm{C}-2000^{\circ} \mathrm{C}\right)$ which permits direct vaporization of many elemental materials.

In order to maintain a stable discharge, a minimum pressure between $10^{-4}$ and $10^{-2}$ Torr is required. The methods used to produce the minimum pressure depend on whether the material has an adequate vapor pressure in the controllable temperature range of the source. Vapor can be delivered to the ionization chamber of an ion source by feeding gaseous and high vapor pressure liquid materials from an external reservoir, by internal vaporization or sublimation of solid materials, or by sputtering from probes mounted in the discharge.

Control difficulties may be encountered with low temperature solids because of heat conduction or radiation from the discharge or hot cathode to the oven. For such materials, heat sinks or radiation shields are often used in order to prevent thermal feedback so that the vapor flow can be controlled adequately. Another technique which can be used is to restrict the flow rate by designing a long low conductance transport tube from the source oven to the ionization chamber. The transport tube may be designed by applying either the Poiseuille or knudsen flow formulas depending on whether the mean free path $\lambda$ of the particle is less than the radius of the tube a or not

$$
F\left(\frac{\text { particles }}{\text { sec }}\right)=\frac{\pi a^{4} P_{\Delta} P}{8 \pi k T \ell}(\text { Poiseuille flow; } \lambda \ll a)
$$




$$
F\left(\frac{\text { particles }}{\sec }\right)=\frac{2 \pi}{3} a^{3}\left(\frac{8 k T}{\pi M}\right)^{\frac{1}{2}} \frac{\Delta P}{\ell K T} \quad(\text { Knudsen flow; } \lambda \gg \text { a) }
$$

where $F$ is the number of gas atoms/molecules flowing per second from a tube of radius, $a$, and length, $\ell, \bar{p}=\left(p_{1}+p_{2}\right) / 2$ is the average pressure in the tube, $\Delta P=P_{2}-P_{1}$ is the pressure drop across the tube, $T$ is the temperature of the oven, $k$ is Boltzmann's constant, $n$ is the viscosity of the gasejus vapor, and $M$ is the atomic or molecular weight. The mean free path of course can be computed from the expression $\lambda=1 / \sqrt{2} n_{0} \pi d_{0}{ }^{2}$ where $n_{0}$ is the number of atom/molecules per unit volume of atomic or molecular diameter $d_{0}$.

High Vapor Pressure Matemals. Approximately 10\% of the elemental materials are gases at room temperature and therefore are easily metered into the discharge chamber by means of a needle valve or other precision control devices. Selieral other gaseous or liquid high vapor pressure molecular compounds exist which may be introduced in a similar manner. Such materials are highly desirable from the standpoint of ion source operation.

Low Vapor Pressure Materials. Approximately $23 \%$ of the elements which are liquid or solid at room temperature have vapor pressures of the order of $10^{-3}$ in the controllable temperature range of most sources $\left(300-1100^{\circ} \mathrm{C}\right)$ which are equipped with provisions for vaporizing the material internally. Materials which cannot be vaporized in elemental form often exist in molecular form and can be vaporized directly in the source oven. The direct vaporization of solid material requires precise temperature control. Because of the time required to reach thermal equilibrium, instantaneous changes in vapor flow rate cannot be made and source operation is therefore more tedious. 
Chemical synthesis. The technique of chemical synthesis of volatile materials in the ion source eliminates some of the difficulties associated with direct vaporization of solids. This method consists of passing a highly reactive gas over the heated elemental materials or their oxides to form more readily volatile compounds. The process can be controlled precisely by externally adjusting the flow rate of che reactive gas. The choice of a suitable reactive gas, of course, depends upon the chemistry of the reactants. A halogenating compound such as $\mathrm{CCl}_{4}$ can be used with many elemental metals or their oxides. The oven temperature need not be precisely controlled but must be operated at a temperature sufficientiy high to ensure the rapid and complete removal of the products of the reaction.

One of the most significant advances in the technology of ion beam formation has come as a result of applying the internal synthesis technique to the platinum and palladium groups of metals. Previously these materials had to be vaporized in very high temperature sources or by sputiering from probes mounted in the ion source discharge due to the lack of stable compounds of these materials suitable for ion source use. In the past few years, workers in Russia ${ }^{33}$ ) and Oak Ridge ${ }^{34}$ ) have developed the halogenation technique for forming intense beams of these elements. The schenre used at Oak Ridge is illustrated in fig. 1. The technique consists of passing CIF 3 over the heated metal which is situated directly beneath the discharge. The vapor feed line and ionization chambers are made of nickel metal which becomes passivated after exposure to fluorine. Ion beam intensities of $10-30 \mathrm{~mA}$ of the elements have been extracted from an ion exit aperture of $4.0 \times 114 \mathrm{~mm}^{2}$ (typical extraction voltage $V_{E x} \cong 50 \mathrm{kV}$ ). The lifetime of the source cathode which is a heated tantalum filament $(\phi=4.5 \mathrm{~mm})$, in general exceeds 40 hours. 


\subsection{FEED MATERIALS FOR ION GENERATION}

Several factors should be considered before selection of a feed material for the desired ion species including: 1) the corrosive nature of the feed material in relation to the exposed components of the source which operate at elevated temperatures; i.e. feed material container, vapor transport tube, ionization chamber, ion extraction aperture, etc. (The use of the chemical synthesis technique (halogenation) can quickly errode components of stainless steel which operate at elevated temperatures; 2) the required ion current; (Usually, the highest ion current of the particular element of interest can be realized whenever the feed material is in its simplest form; i.e. elemental or diatomic molecular compounds contain a higher percentage of the desired ion beam component. Plasma discharge sources generally operate under space charge limited conditions - unwanted ions from the other molecular constituents are therefore in competition with the desired species.); 3) the compatibility of the feed material vapor pressure with the temperature range of the source. Consideration must also be given as to whether higher intensities which might be realized by the vaporization of solid elemental or simple molecular compounds and the necessary precise oven temperature control and operator interaction outweighs the advantages gained by using a high vapor pressure liquid or gaseous compound which can be regulated by a simple needle valve but produces perhaps lower intensities.

A list of feed materials which have been determined experimentally over a period of many years by electromagnetic isotopes separations groups is given in Table 1. The data were almost all taken from the compilations of the Oak Ridge National Laboratory isotopes separation group who have accumulated more data of this type than any other group in the world ${ }^{24}$ ). 
Also included are calutron ion source average feed rate data, average and maximum magnetically analyzed current densities for each of the elements processed in the Oak Ridge isotopes separation program. The average current density data are averages of the maxima associated with all separation series which often involve several isotope separators - operating over a period of many months. The highest current density associated with all of the separations of a given element was taken as the maximum. (The purpose for displaying these data is to provide the reader with information for scaling and perhaps predicting outputs and feed rates for slit type sources such as the magnetron ${ }^{30,31}$ ), Freeman ${ }^{32}$ ), and other variations of the calutron source - all of which produce essentially the same plasma densities and have approximately the same material utilization efficiencies.) Comparison of extracted current densities must take into consideration differences in the extraction voltages and electrode spacings of the sources because of the space charge limited flow behavior of plasma discharge sources. Typical calutron source data are: extraction potential difference: $V_{E x}=\sim 50 \mathrm{kV}$; electrode spacing: $1.75 \mathrm{~cm}$; and aperture area: $4.8 \times 127 \mathrm{~mm}^{2}$.

\subsection{MATERIALS OF CONSTRUCTION}

Materials for ion source components should be selected on the basis of their compatibility with the functional and operational requirements. The components may be required to operate for extended periods of time at elevated temperatures in very corrosive and errosive environments such as those which exist in plasma discharge chambers or they may only be used as support structure components which may operate at moderate temperatures in non-corrosive environments. Among the properties which may or may not be important in the 
selection process are: mechanical strength, thermal conductivity, thermal expansion compatibility with mating components, machinability, corrosion resistance to feed materials, sputtering characteristics, cost, availability and dielectric properties in the case of insulators. Generally speaking, there are no ideal materials for construction which are low in cost, easy to machine, and will operate at elevated temperatures in corrosive environments. However, there are several materials which meet most of the operational requirements satisfactorily. A few of the commonly used materials are listed below.

Copper: Copper is widely used for electrical conductors and in non-corrosive and non-errosive environments due to its excellent electrical conductivity, heat transfer, and machinability properties. However, the material is very soft, reacts chemically rather easily and has a high sputtering coefficient. It should be considered for use for components which operate at temperatures $T \leq 900^{\circ} \mathrm{C}$ in non-corrosive areas and where it is not exposed to ion bombardment.

High Density Carbon: This material is very often used for fabrication of medium $\left(T \leq 1100^{\circ} \mathrm{C}\right)$ and high temperature $\left(T \leq 3000^{\circ} \mathrm{C}\right)$ ion source components such as discharge chambers, feed material containers, ovens, heating elements, extraction apertures, electrodes, etc. It has excellent machining characteristics and is surprisingly tough and durable. The material does not react at fast rates with corrosive feed materials, has a low sputtering coefficient and can be operated at elevated temperatures. On the other hand, it does occlude gases when exposed to air and subsequently gases badly during ion source start up. Groups I and II elements tend to diffuse rather rapidiy into the material at elevated temperatures which after extended periods of operation can lead to mechanical degradation of the material. 
Stainless Steel: Staili?ess steel is commoniy used for components which operate at moderately low temperatures such as the vacuum flange, extraction electrodes and other support structures. It may also be used for discharge chambers, feed material containers, extra cion apertures, electrodes, heat shielding etc. in sources which operate at temperatures $\leq 1100^{\circ} \mathrm{C}$. The material has excellent mechanical strength and good machinability properties but reacts rapidly at elevated temperatures, especially with the halogens.

Nickel, Iron, and Mild Steel: Iron and mild steel, because of their magnetic properties are almost exclusively used for magnetic flux circuitry and magnetic field flux concentration such as in the uno and duoplasmatron ion sources. Nickel is also magnetic and should not be used in bulk quantities in areas where magnetic field distortions might affect source operation and performance. However, it is an excellent coating material for protection against chemically active feed materials such as the halogens because it tends to passivate after halogen exposure. It has good machining properties and can be operated at temperatures $T \leq 2000^{\circ} \mathrm{C}$.

Mo iybderam: Molybdenum is a refractory material and an excellent choice for ion source components which operate at temperature $T \leq 2000^{\circ} \mathrm{C}$. It can be machined more easily and is lower in cost than other refractory metals and therefore can be used to fabricate various ion source parts such as ionization chambers, extraction apertures, heat shielding, etc. It appears to chemically errode slowly in applications where it is exposed to active feed materials. It also does not crystalize as badly and become as brittle as does tungsten. 
Tantaium: Tantalum is also a refractory material and can be operated at temperatures $T \leq 2600^{\circ} \mathrm{C}$. The material can be machined relatively easily and therefore has been used for various ion source components which operate at high temperatures. It has been used, for ionization chambers, extraction apertures, heat shielding, etc, and is used wideiy as material for hot or cold cathodes. It is very susceptible, at elevated temperature to chemical reactions with nitrogen, oxygen, and other corrosive feed materials.

Tungsten: Tungsten is also refractory and can be operated at temperatures $T \leq 3000^{\circ} \mathrm{C}$. It is one of the best choices and most widely used filament materials. However, it is usually brittle and has poor machining characteristics. It also tends to crystalize and break easily after high temperature usage. Tungsten is susceptible to reactions with oxygen but seems to resist halogenation better than most materials at elevated temperatures.

Platinum, Gold: These materials are used sparingly because of their high cost and poor mechanical strength. Thej are the best choice, however, in terms of their corrosive resistance to chemically active feed materials. They can be used as protective coatings for components which are susceptible to chemical corrosion and errosion. Applications should be made at temperatures $T \leq 1000^{\circ} \mathrm{C}$ for gold and $T \leq 1600^{\circ} \mathrm{C}$ for platinum. Both materials sputter easily and should not be used in heavy ion bombardment situations.

Rhenizom: Rhenium is very costly but is used occasionally for hot cathode materials and surface ionization applications, etc. It reacts slowly with the halogens but does react with oxygen at high temperatures. 
Insuiators: There are several insulating materials available for ion source use including alumina, quartz, boron nitride and machinable glass materials. Alumina is the most predaminantly used high voltage insulator because of $i$ ts excellent dielectric properties. It also is the choice for high temperature applications.

For lower temperature applications, boron nitride is frequently used because of its excellent machinability. However, it is very soft and has poor mechanical strength. It will react with corrosive feed materials when exposed at elevated temperatures. At very high temperatures $\left(T \leq 2000^{\circ} \mathrm{C}\right)$ it begins to decompose. It also picks up moisture readily when exposed to air and subsequently out gases badly during source start up.

In recent years machinable glasses have been made available which can be machined in almost any configuration. They also can be threaded but are very brittle and therefore are subject to easy breakage. The recommended upper temperature limit is $\sim T \leq 1000^{\circ} \mathrm{C}$ for unstressed use.

\subsection{ELEMENTARY PHYSICAL PROCESSES IN ARC PLASMA DISCHARGES}

Ions may be produced from neutral vapors by energetic photons, electron;, or ions with energies above the threshold for ionization of the medium. The principle method for producing a highly ionized medium from which intense positive ion beams can be extracted is by creation of an electrical discharge in the gaseous vapor. The discharge is most generally effected by electron impact or high frequency electric fields, al though high power laser technology is rapidly advancing and other resonance ionization processes may be used in the future. In this report particular attention will be given 
to sources which utilize heated filaments to initiate the discharge, since this particular type of source continces to be the most commonly used and most versatile of existing sources due to their wide range of ion species capabilities. Less attention will be given to high frequency and Penning discharge sources, since they ore limited as far as species versatility is concerned.

Ion Source Configurations - Discharge Initiation. In arc plasma discharges, the discharge is initiated and sustained by accelerating electrons whi h are thcmionically emitted from a heated cathode to energies above the threshold for ionization of the gaseous vapor. The discharges are almost always directed by a magnetic field - usually oriented paraliel to the direction of electron acceleration with a few exceptions such as the magnetron ${ }^{30,31}$ ) or Freeman ${ }^{32}$ ) sources where electron acceleration is perpendicular to the auxilliary magnetic field.

Figure 2 illustrates two commonly used discharge configurations. Note that the ions are extracted in a direction parallel to the discharge or perpendicular to the direction of the discharge. The former method is often referred to as an axial or end extraction geometry while extraction perpendicular to the discharge axis is often referred to as a side or radial extraction geometry. The end extraction geometry is compatible with circular extraction apertures while the side extraction geometry permits extraction from the length of the plasma column from slit type apertures. The vaporous material, which must be introduced at a rate sufficiently high to sustain a stable discharge is metered as a gas or high vapor pressure liquid or from an adiacent oven. The side extraction geometry is that of the calutron ion source developed in the early 1940's for the electromagnetic separation of 
the isotopes of uranium ${ }^{29}$ ) while the geometry shown in fig. 2 is the orientation employed in axial geometry configurations such as the Scandinavian source ${ }^{27}$ ).

The ensemble of complex physical and chemical processes, which are in dynamic equilibrium in stable discharges containing chemically active elements, make detailed analysis and understanding of such media difficult, if not impossible. Several investigations have been made of hot filament generated discharges over the years which have provided the basic information which has led to our present understanding of such processes (e.g. Bohm et al. ${ }^{35}$ ), Almen and Nielsen ${ }^{36}$ ), and $\left(\right.$ havet $\left.{ }^{37}\right)$ ). However, these studies, by using simple noble gases in the investigations, avoided the additional compexities associated with typical discharges in heavy ion sources which may involve simultaneously several different chemically active elements. The following discussion of the fundamental processes which take place in hot filament generated discharges is principally based on the results of the compreher.sive studies made during the early days of the development of the calutron ion source $^{35}$ ).

The discharge in hot filament sources is initiated and sustained primarily by thermionically emitted electrons from the heated filament which are accelerated to energies sufficiently high to produce ionization of the medium. The emission current density is given by the well-known DushmanRichardson equation

$$
j\left(A / \mathrm{cm}^{2}\right)=A(1-r) T^{2} e^{-\phi / k T}
$$

where $A$ is a constant with value $A=120 \mathrm{~A} / \mathrm{cm}^{2}, r$ is the reflection coefficient at the metal surface, $T$ is the absolute temperature, $\phi$ is the work function of the metal and $k$ is Boltzmann's constant. From the equation, we can readily 
see that high work function metals must be hed ted to higher temperatures than those with lower work functions for equivalent currents. In practice, the emission current may not reach the saturation value predicted by Eq. (3) because of space charge effects. However, theoretical values can be achieved if the cathode and anode potential is sufficiently high so that electrons are extracted as fast as they are emitted. In the case of a plasma discharge situation, the theoretical value can be achieved by positive ions arriving at the filamelit which can neutralize space charge effects.

Initiation of an arc discharge is accomplished by introducing a small amount of gas or vapor into the discharge chamber at flow rates high enough to istablish an adequate pressure in the anode-cathode region and by accelerating the electrons to an energy sufficient to ionize a fraction of the vapor. In this way a medium with piasma-1ike properties is oroduced.

Plasma Characteristios - Sheatin Formation. A plasma is defined as a neutral or quasi-neutral isotropic distribution of positive and negatively charcod ions and electrons at constant potential. The condition that the plasma be quasi-neutral requires that the number of positive charges per unit volume, $n+$, be approximately equal to the number of negative charges per unit volume, $n$ - or $n+\equiv n-$. If it is assumed that the plasma is made up of $n_{e}$ electrons per unit volume and $n+$ singly charged positive ions per unit volume then the condition may be expressed as $n+\cong n_{e}$.

One of the most important characteristics of a plasma is that it attempts to preserve its field-free interior from external perturbing forces by establishing a double layer or sheath around insulated probes placed in contact with the plasma. At the plasme sheath boundary the electric field must be zero sirce a potential drop of significance cannot be maintained ty the 
plasma. Under space charge limited electron current conditions, the field near the filament is also zero. Because the electric field is maintained between these points of zero potential, there must be equal numbers of electrons and $i$ ins. The electrons are concentrated near the filament and the ions near the plasma boundary. Figure 3 illustrates the formation of a double layer surrounding a hot filament. The potential drop is maintained between the two distributions - the electrons being attracted by the ions the ions by the electrons. Because of the greater mass of the ions, the ion moves more slowly and thus a lower ion current is required to maintain space charge neutrality.

Under space charge limited flow conditions with 10 plasma boundary present, the electron current would approximatnly follow the familiar Langmuir ${ }^{38}$ ) space charged limited flow formula for a planar diode

$$
j\left(A / \mathrm{cm}^{2}\right)=\frac{4}{9} \varepsilon_{0}\left(\frac{2 q}{m_{e}}\right)^{1 / 2} \underline{v^{3 / 2}}
$$

where $q$ is the electronic charge, $m_{e}$ is the electranic mass, $v$ is the potential drop between cathode and anode and $d$ the electrode spacing.

In the presence of a plasma, the sheath thickness is greater than it would be for a sheath containing only fositive ions. This is due to the fact that the electrons re luce the space charge in the sheath so that a greater distance is required to adsorb the potential drop. The actual sheath thickness according to Bohm ${ }^{35}$ ) is give.i by

$$
x=\frac{2}{3}\left(\frac{\varepsilon_{0}}{j+}\right)^{1 / 2}\left(\frac{2 q}{M}\right)^{1 / 4} v^{3 / 4}
$$


The sheath thickness given by $x$ is increased by the factor $\&$ over that for the case of a ion sheatri containing only positive ions of mass $M$. For For the case of maximum electron current, the constant is approximately $1.36^{35}$ ). Equation (5) assumes that the field terminates abruptly at the plasma boundary. However, from classical electrodynamic theory, we know that static fields penetrate into the plasma-dropping off exponentially to a depth o given by

$$
s_{\text {plasma }} \cong \frac{c}{\omega_{p}}
$$

where $\omega_{p}=\left(4 \pi n_{e} / m_{e}\right)^{1 / 2}$,e is the plasma frequercy, $n_{e}$ is the plasma density, $\mathrm{m}_{\mathrm{e}}$ is the electronic mass, and $\mathrm{e}$ is the electronic charge. For laboratory observed plasma densities corresponding to $n_{e} 10^{12} \rightarrow 10^{14}$, the field penetration depth will be of the order of 5 to $0.5 \mathrm{~mm}$ but drops off exponentially to this depth. Figure 4 illustrates schematically the potential distribution in the sheath region. Because of the penetration of the field into the plasma, positive ions at depth $\delta$ are accelerated toward the cathode. A schematic of a plasma discharge illustrating penetration of the externa: field to a depth $s$ is shown in fig. 5 . Bohm, after solution to Poisson's equation, arrives at the fact that ions must reach the plasma sheath with a kinetic energy of at least half of the plasma electron temperature

$$
\mathrm{Ti} \geq \frac{1}{2} \mathrm{Te}
$$

which is of the order of $1 \mathrm{eV}\left[\right.$ ref. $\left.{ }^{2}, 1\right]$.

Stable Discharge Criteria and Ion Formation. Iri order to maintain a stable discharge, the relationship between electron, $j_{e}$, and ion current density, $j+$ flowing across the sheath must satisfy the following inequality 


$$
j_{e} \leq \gamma\left(\frac{M}{m_{e}}\right)^{1 / 2} j+
$$

where $M$ and $m_{e}$ are the masses of the positive ions and electrons respectively and $Y$ is a correction factor which varies with the state of the cathode and has values between $1 / 2$ and $\left.2 / 3^{35}\right)$. Equation $(8)$ is referred to as the Langmuir criterion for a stable discharge ${ }^{39}$ ).

The Langmuir criterion provides an upper limit for the electron current density emitted by the filament. When the ratio of positive ions arriving to electrons leaving the filament falls below the limit imposed by Eq. ( 8 ), the discharge will become very unstable and eventually go out. The rate of generation of positive ions is directly proportional to pressure and therefore, there is a critical pressure below v hich the condition imposed by Eq. (8) does not hold.

The probability of creating a fositive particle in a discharge of arc current density, $j_{a}$, is given by

$$
P=1-e^{-\sigma_{i} j_{a} 2 / a \bar{v}_{0}}
$$

Fitiere $\sigma_{i}$ is the cross section for ionization, $\ell$ is the average distance traveled by a neutral atom of mean velocity $v_{0}$ in the discharge and $q$ is the magnitude of the charge on the electron. Therefore, the rate of ion generation in terms of current density is

$$
\left.j_{+} \cong q \frac{n_{0} \bar{v}_{0}}{4} \quad P_{(} \sigma_{i}, j_{2}, l, \bar{v}_{0}\right) \text {. }
$$

After steady state conditions have wten reached, the rate of ion generation is just balanced by tine rate at which ions leave the column. From Eq. (7), the ion current density arriving at the sheath edge is 


$$
j_{+}=q n+\left(\frac{k T_{e}}{M}\right)^{1 / 2} \text {. }
$$

If we assume that the rield penetrates to a distance $\delta$ into the plasma, and losses occur with equal probability at each end, then the fractional loss at the ends of the column $j_{+\|}(105 s)$ (see fig. 5) is given by

$$
j_{+1}(\text { loss }) \cdot \frac{2 \hat{0}}{Z} q n+\left(\frac{k T e}{M}\right)^{1 / 2} \text {. }
$$

The fractional rate of loss of ions across the magnetic fieid through diffusion processes (after Bohm ${ }^{35}$ ) is given by

$$
j_{+} \perp(10 s s) \cong 4 q n+\frac{\rho}{Z}\left(\frac{k T_{e}}{M}\right)^{1 / 2}
$$

where $\rho$ is the characteristic distance at which the ion density $n+$ drops to 1/e of its value in the column.

After equating the rate of loss to ion generation and utilizing the Langmuir stability criterion, we obtain expressions for the minimum flow rate $f$, the minimum neutral density $n_{0}$ and the minimum pressure $p_{\min }$ necessary to maintain at stable discharge. They are

$$
\begin{aligned}
& f \geq \frac{4}{Z} \bar{\gamma}\left(\rho+\frac{\delta}{2}\right)\left(\frac{m_{e}}{M}\right)^{1 / 2} \frac{j_{a}}{p} \\
& n_{0} \geq \frac{16}{Z} \frac{\gamma}{\gamma}\left(\rho+\frac{\delta}{2}\right)\left(\frac{\pi m_{e}}{8 k T_{o}}\right)^{1 / 2} \frac{j_{a}}{p} \\
& p_{\min } \geq \frac{8}{Z} \frac{\gamma}{\gamma}\left(\rho+\frac{\delta}{2}\right)\left(\frac{\pi m_{e} k T_{0}}{2}\right)^{1 / 2} \frac{j_{a}}{p}
\end{aligned}
$$

where $\bar{v}_{0}=\left(\frac{8}{\pi} \frac{k T}{M}\right)^{1 / 2}$ has been used for the average thermal velocity of the neutral atoms and the arc current density $j_{a}$ has been equated to $j_{e}$. 
Minimum pressures for stable discharge generally lie between $10^{-4}$ and $10^{-2}$ Torr for most ion sources. However, the radio frequency source generally requires pressures between $10^{-2}$ and $10^{-1}$ Torr.

\subsection{THEORETICAL ESTIMATE OF THE CATHODE LIFETIME}

In heavy ion sources, the cathode lifetime is more often than not the limiting factor which determines the sustained length of source operation. The nature of the ion generation mechanism which produces sputtering of the cathode and various chemical reactions which the cathode may be subjected to, errodes away the cathode. In most cases, the principle mechanism which eventually wears the filament or cathode to the point of breakage or arc extinction in the case of cold cathode sources, appears to be that of physical sputtering. However, high concentrations of oxygen severely reduces the lifetime of filaments made of chemically active elements such as $T a$ and $W$, etc.

A formula can readily be derived which relates cathode lifetime to the physical properties of the cathode materials by using the previously discussed elementary concepts in conjunction with the applicable sigmund formula ${ }^{40}$ ) for sputtering. In this analysis, the wear mechanism is assumed to be solely due to physical sputtering.

The amrunt of material from the cathode removed per unit time depends on the rate of positive ion bombardment and sputtering ratio.

$$
\frac{d N_{0}}{d \ell}=\frac{d N+}{d t} S[\text { atoms }] \text {. }
$$

Singly charged ions bombard the cathode with an energy $T_{c}$ equal to the sum of the energy received across the plasma sheath plus the energy of arrival at 
the sheath edge, $T_{i}$

where

$$
T_{c}=T_{a}+T_{p}+T_{i}
$$

$$
T_{a}=q V_{a} ; T_{i} \cong \frac{1}{2} T_{e} ; T_{p} \cong q V_{p} \text {. }
$$

In the previous expression, $V_{a}$ is the discharge voltage, $T_{e}$ is the electron temperature of the plasma ( $\sim 2 \mathrm{eV}$ ), and $V_{p}$ i) the plasma potential (iypically $5-20 \mathrm{~V})$. The range of potential differences over which most hot or cold cathode discharges operate is between $30 \leq V_{a} \leq 1000 \mathrm{~V}$. In the range of cathode bombarding ion energies, the sputtering ratio $S$ is linearly related to the ion energy by the sigmund formula ${ }^{40}$ ) for low energy sputtering

$$
S\left[\text { atoms/ion] }=\frac{3}{4 \pi^{2}} \frac{\alpha \lambda T_{c}}{U_{0}} \cong \frac{3}{4 \pi^{2}} \frac{\alpha \lambda}{U_{0}} q V_{a}\right.
$$

where $\alpha$ is a function of the ratio of target to bombarding ion mass $m_{2} / m_{1}$ which has been numerically calculated by sigmund ${ }^{40}$ ) and experimentaily extracted from sputtering data by Andersen ${ }^{41}$ ). $\lambda$ is given by

$$
\lambda=\frac{4 M_{1} M_{2}}{\left(M_{1}+M_{2}\right)^{2}}
$$

and $U_{0}$ is the heat of sublimation of the cathode material.

The arc current density $j_{a}$ is the sum of the ion and electron current densities

$$
j_{a}=j_{e}+j+
$$

Using the Langmuir criterion for a stable discharge, we obtain an expression for $j+$ in terms of $j_{a}$

$$
j+=\frac{j_{a}}{1+\gamma \sqrt{M_{1} / m_{e}}} .
$$

Thus

$$
\frac{d N+}{d t}=j_{+} A=\frac{I_{a}}{T+r / M_{1} / m_{e}}
$$

where $A$ is the area of the cathode. 
The rate of loss per unit time is given by

so that

$$
\frac{d N_{0}}{d t} \equiv-\frac{3}{4} \frac{\alpha \lambda}{\pi^{2}} \frac{1}{\left(1+\gamma \sqrt{m_{1} / m_{e}}\right)} \frac{q}{\rho_{0}} \frac{I_{a} V_{a}}{U_{0}},
$$

$$
t \leq \frac{4}{3} \frac{\pi^{2} U_{0} \rho_{0}}{\alpha \lambda q I_{a} V_{a} M_{2}}\left(1+\gamma \sqrt{M_{1} / m_{e}}\right) \int_{0}^{T_{0}} d \tau
$$

where $\rho_{0}$ is the density of the cathode material and $d \tau$ is the differential volume of the material being sputtered.

Figure 6 shows the theoretical upper limit of a few equidiameter cathode materials subjected to uniform argon bombardment predicted from eq. (24) for the indicated source and filament parameters. The theory does not take into account the influence of the neutral particles which continually strike t'? surface and reflect or impede the sputtering process. As we know a fraction of the cathode material may subsequently become ionized and accelerated back to the cathode which would tend to increase the sputtering in this case - this is not taken into consideration. The equation appears to predict lifetimes which agree reasonabiy well witn those experienced in practice. In reality the filament probably never or rarely wears completely through by sputtering but often breaks due to melting as a result of ohmic heating after having been worn thin by ion errosion. Because of the several factors which determine the length of cathode lifetime - lifetimes vary widely with nominal values for $T_{a}$ and $W$ filaments ranging between 25 and 100 hours depending on the discharge parameters and types and concentrations of chemically active materials in the discharge.

The choices of filament materials are very limited and no ideal material exists. (The ideal material should have a high melting temiperature, a very low sputtering ratio and be chemically inert.) The filament cross sectional area, length, and resistivity at the operation temperature determine the total 
resistance of the filament which in turn specifies the minimum power required to drive the filament to the desired temperature. Because of the different resistivities for the various cathode materials, the filament diameters will be different for equal resistance values so that the actual lifetimes will be affected. For example, the resistivity of tantalum is 21.75 that of tungstin so that a tantalum filament is increased in diameter relative to that of tungsten filament for equivalent resistances and thus the relative lifetime is increased.

\subsection{EXTRACTION OF IONS FROM A PJAASMA}

The Plasma Boundary: Extraction of ions from a plasma boundary is accomplished by applying a potential, $V_{E x}$ between the exit aperture and an extraction electrode which is negative with respect to the plasma potential $V_{p}$. At the exit boundary, a sheath is formed between the plasma surface area, and the extraction electrode which is made of ions extracted from the plasma. Due to the difference in the mobilities of electrons and positive ions, the plasma potential $V_{p}$ is slightly positive with respect to the walls of the ionization chamber of the source and usually is of the order of 5 to $20 \mathrm{~V}$.

The ion extraction boundary (meniscus) may assume a variety of shapes depending on the plasma density $n_{e}$, variations in plasma density, and the potential $V_{E x}$. For fixed ion source parameters and low extraction voltage $V_{E x}$ the plasma will assume a convex shape. As $V_{E x}$ is gradually increased more positive ions are extracted and the boundary recedes uncil it becomes flat and finally becomes concave at appropriateily high values of $V_{E x}$. Since the shape of the extraction plasma boundary varies with extraction potential $V_{E x}$ and source parameters (arc current, arc voltage, vapor flow rate, and magnetic field) - it therefore acts as the first and most important lens in the system. And thus plays an important roll in the final angular divergence of the ion beam as well as beam 
quality. Plasma boundary shapes which may result during source operation are illustrated in figs. $7 a, b, c$, and $d$. Plasma distortions due to complex plasma boundary shapes (fig. 7d) of course aberrates the beam which may seriously degrade the quality of the ion beam.

The final angular divergence is effected by the plasma boundary curvature, space charge, electrode geometry, and lens effects of the extraction electrode system. Space charge forces lead to the formation of a waist in convergent beams (fig. $7 a$ ) rather than a sharp cross over. The virtual focus (or virtual object) serves as the object for the mass analysis system unless there are additional lenses present. The virtual object will change during source operation which results in a movement of the image focal plane of the analyzer. Due to the fact that the source aperture and the virtual object differ in physical positions, location of beam defining slits or apertures should be made with this effect in mind. The defining aperture thus should be positioned at the observed focal point for typical ien source operation and optimum resolution. The virtual object will be smaller than the source extraction aperture and therefore the image in the plane of analysis will be smaller. Thus it is important in terms of resolution to have the beam defining apertures positioned correctly.

Plasma Instabilities. A characteristic of plasma discharge ion sources is the acoustical phenomenon known as "hash". The oscillations usually span a frequency range between 20 and $500 \mathrm{KHz}$ and arise whenever the equilibrium distributions of electrons or ions in the plasma are disturbed. During periods of such instabilities, ion beams may be intensity modulated up to $100 \%$. The oscillations usually occur near the minimum pressure for a stable discharge and can be damped considerably by increasing the discharge chamber pressure slightly. During such oscillations, the extract boundary 
rapidly changes shape in oscillatory fashion and therefore the beam emittance rapidly varies with time. Also during such oscillations, equilibrium space charge compensation is incomplete due to rapid density variations of the extracted beam.

The Ion cumpent. The ion current density which can be extracted from a plasma boundary generally exhibits a $V_{E x}{ }^{3 / 2}$ dependence. The form of the current density versus extraction voltage $V_{E x}$ was experimentally detemined by Rautenbach ${ }^{42}$ ) to have the form

$$
j=C\left(\frac{q}{M}\right)^{1 / 2} V_{E x} 3 / 2
$$

where the constant $C$ depends on the source deometry, $q$ is the charge, and $M$ is the mass of the ion. Several experimental verifications of the space charge limited form of the current density versus extraction voltage (including Almen and Nielsen ${ }^{43}$ ), and Chavet $^{37}$ )) have been made

$$
j=\frac{\text { const }}{\sqrt{M}} \frac{V_{E x}{ }^{3 / 2}}{d^{2}}
$$

where the constant depends on the source geometry and $d$ is the electrode spacing.

It should be pointed out that many species of ions may be generated in the plasma with different masses and different charge states and therefore the space charge limited current may be comprised of many charge states and ion masses which are in the discharge. The presence of other charge states and masses will substantially reduce the beam intensity of the desired species. This is especially true when the ion is generated from a complex molecular feed material or when an auxilliary discharge support gas is used. Magnetically analyzed calutron ion current density data from various feed materials versus atomic number of the desired species as shown in fig. 8 illustrate this point. 
We note that atomic or simple molecular compounds yield the highest current densities of the desired species while the current densities are much lower for more complex feed materials in comparison.

Because of the capability of adjusting the source parameters for optimum production of the desired component, some marginal species differentiation is possible. As a rule, the source discharge potential should be maintained at approximately $5 \times I_{i}$ where $I_{i}$ is the first ionization potential of the desired species. This setting should roughly correspond to the maximum in the first ionization curve. Typical electron impact ionization curves are shown in fig. 9 .

Material utilization efficiency. The material utilization efficiency of an ion source is often an important consideration and is defined as the ratio of the flux of charged particles, $j_{+}$, to the total flux of charged and neutral particles $j_{0}$ flowing across the ion extraction boundary or

$$
n=\frac{j_{+}}{j_{+}+j_{0}} \text {. }
$$

The positive ion current density is given by the formula of Bohm ${ }^{35}$ ) and is

$$
j_{+}=0.4 q n+\left(\frac{2 k T e}{M}\right)^{1 / 2}
$$

where $k$ is Boltzmann's constant and $T_{e}$ is the electron temperature of the plasma. The equivalent current density of neutrals flowing across the sheath is given by the well-known formula from the kinetic theory of gases

$$
j_{0}=q \frac{n \bar{v}_{0}}{4}=q n\left(\frac{k T_{0}}{2 \pi M}\right)^{l / 2}
$$

where $T_{0}$ is the temperature of the neutrals of mass, M. Substituting expressions (29) and (30) into eq. (28) we obtain

$$
n=\left(1+0.7 \frac{n}{n^{+}}\left(\frac{T_{0}}{T_{e}}\right)^{1 / 2}\right)^{-1} \text {. }
$$


Ion source performance measurements are very of ten màde immediately after extraction and therefore include all ion species generated by the discharge. In such measurements the natural tendency is to adjust all ion source parameters to achieve a maximum extracted ion current without regard to beam quality, space charge effects or the spectrum of charges or masses which make up the extracted beam. Therefore, measurements made under these conditions are of limited value. The most important component in the spectrum of ion beams generated by the ion source is the desired ion beam which must be optimally transmitted through the beam handling equipment. The ion source parameters and other optical components are adjusted so as to maximize the current through an aperture at some point after mass analyzation. The material efficiency measured in this way may be expressed as

$$
n=4 \frac{I(q, M)}{q n_{0} \bar{v}_{0} A}=\left(\frac{2 \pi M}{k T_{0}}\right)^{i} ; ? \frac{I(q, M)}{q n_{0} A}
$$

where $I$ is the current of the wanted species of charge $q$ and mass $M$ and $A$ is the area of the ion source extraction aperture.

\subsection{OPTICS OF THE EXTRACTION REGION}

Several investigators, including Harrison ${ }^{43}$ ) Chevet and Bernas ${ }^{44}$ ), Green ${ }^{45}$ ) and Thompson ${ }^{46}$ ), have made elementary analyses of the ion optics of the extraction region of plasma source based on the Langmuir-Blodsact theoretical formulations for current flow between cylindrical and spherical electrodes ${ }^{47,48}$ ) or through simple apertures as treated by Pierce ${ }^{49}$ ) and by Brewer ${ }^{50}$ ). Excellent reviews on the subject has been included in papers by $\mathrm{Green}^{8,15}$ ). 
Imoortant space-charge flow solutions to Poisson's equation have been made by Langmuir for rectilinear flow between parallel plates ${ }^{38}$ ) and by Langmuir and Blodgett ${ }^{47,48}$, for flow between concentric cylinders and spheres. Methods of solutions for the cylindrical and spherical geometries were first given by Langmuir and Compton ${ }^{51}$ ).

Poisson's equation for the potential distribution in the presence of space charge density : is

$$
\nabla^{2} s=-\frac{\dot{j}}{\dot{s}_{0}}
$$

where $\Sigma_{0}$ is the permittivity of free space. Equation (33) can be solved analytically for the current I flowing in a planar diode (parallel plate) configuration which is

$$
I=\frac{4}{9}=_{0}\left(\frac{2 q}{M}\right) \frac{v^{3 / 2}}{d^{2}} .
$$

In terms of perveance $P$, the solution is

$$
P=\frac{A}{V^{3 / 2}}\left(\frac{A}{Z}\right)^{1 / 2}=\frac{4}{9} \varepsilon_{0}\left(\frac{2 e}{M_{p}}\right)^{1 / 2} \frac{A_{c}}{d^{2}}
$$

where $V$ is the potential difference and $d$ is the spacing between the anode and cathode, $q$ is the charge on the electron, $M_{p}$ is the mass of the proton, $A_{c}$ is the area of the cathode, $M$ is the atomic weight of the ion, and $\varepsilon_{c}$ is the permittivity of free space.

In general, analytic solutions cannot be obtained for the concentric cylindrical and spherical electrode configurations and therefore approximate solutions must be made. For rectilinear current flow in the cylindrical geometry, the soivtion to Poisson's equation is taken to be 


$$
I=\frac{16 \pi}{9}\left(\frac{2 q}{M}\right)^{1 / 2}=\frac{v^{3 / 2}}{x^{2}}
$$

where $a\left(r_{a} / r_{c}\right)$ is a dimensionless parameter which is a function of the ratio of the anode $r_{a}$ to cathode $r_{c}$ radii. It can be shown that the parameter a has the series solution

$$
x=r-0.3 r^{2}+0.075 r^{3} \ldots
$$

with $\gamma=$ in $r_{d} / r_{c}$. In terms of perveance $P$, eq. (36) becomes

$$
\begin{aligned}
P=\frac{I}{V^{3 / 2}}\left(\frac{A}{Z}\right)^{1 / 2}= & \frac{16 \pi}{9}\left(\frac{2 e}{M_{p}}\right)^{1 / 2} \frac{\Xi_{0}}{a^{2}} \\
& \text { (spherical geometry). }
\end{aligned}
$$

Similiarly an expression for the current flowing between two concentric cylinders cun be a ained

$$
I=\frac{8 \pi}{9}\left(\frac{2 q}{M}\right)^{1 / 2}=0 \frac{v^{3 / 2} q}{s^{2} r_{a}}
$$

where $z$ is the length of the cylindrical systern. The perveance for this geometry is

$$
\begin{array}{r}
P=\frac{I}{V^{3 / 2}}\left(\frac{A}{Z}\right)^{1 / 2}=\frac{8 \pi}{9}\left(\frac{2 e}{M_{p}}\right)^{1 / 2}=\frac{z}{B^{2} r_{a}} \\
\text { (cylindrical geometry). }
\end{array}
$$

The function $B\left(r_{a} / r_{c}\right)$ has the solution

$$
B=r-\frac{2}{5} r^{2}+\frac{11}{120} r^{3} . .
$$

where again $\gamma=2 n r_{a} / r_{c}$. Values for $\alpha, \beta$, and $\gamma$ have been tabulated as a function of $r_{a} / r_{c}$ and $r_{c} / r_{a}$ by Langmuir and Blodgett 47,48 ).

The previous expressions have been applied to the two electrode exraction geometry illustrated in fig. 10 to obtain the space charge 1 imited flow between the curved sector segments of solid spherical or cylindrical 
electrodes. The cathode is taken to be $r_{c}$ and the anode radius $r_{a}$ is calculated from the difference between $r_{c}$ and $d$, the anode spacing.

Because of similiarities between the solid electron and ion emission plasma boundaries, several investigators have proposed that the same analytical procedure can be applied to the case of ion emission from a curved plasma boundary. Application of the procedure to the case of emission from a spherical sector boundary of aperture radius yields an expression for the perveance $P$

$$
\begin{aligned}
P=\frac{I}{v^{3 / 2}}\left(\frac{A}{2}\right)^{1 / 2}=1.72 \times 10^{-7} \frac{a^{2}}{d^{2}}\left(1-1.6 \frac{d}{r_{c}}\right. \\
\text { (spherical emission boundary) }
\end{aligned}
$$

and

$$
P=\frac{I}{V^{3 / 2}}\left(\frac{A}{Z}\right)^{1 / 2}=1.14 \times 10^{-7} \frac{\mathrm{a} \ell}{\mathrm{d}^{2}}\left(1-0.8 \frac{\mathrm{d}}{\mathrm{r}_{\mathrm{C}}}\right.
$$

(cylindrical emission boundary)

for the case of a cylindrical sector emission boundary of width 2a (after Green $\left.\left.{ }^{8}\right)\right)$. In both cases, it is assumed that $r_{c} \gg d$. The expansion has been carried to order $d / r_{c}$.

If we define the perveance $P$ in terms of the perveance for the parallel plate arrangement for protons, $P_{C}$ for the two types of extraction apertures then

$$
P=P_{c}\left(1-1.6 \frac{d}{r_{c}}\right) \text { (circular aperture) }
$$

and

$$
P=P_{c}\left(1-0.8 \frac{d}{r_{c}}\right) \text { (slit aperture). }
$$

Whenever the radius of curvature of the plasma is positive $P<P_{C}$ and the angular divergence is convergent. Conversely, whenever the radius of the 
plasma is negative, $\rho>\rho_{c}$ and the beam is divergent. Thus we see that space charge limited currents may vary depending on the source discharge parameters.

The previous analysis does - t. take into consideration the presence of the aperture in the second electrude which alters the particle trajectories because of transverse electric field components. The effect of this aperture may be analyzed in terms of the well-known Davissol ablick ${ }^{52}$ ) thin lens formula taking into account modification of the vacuum field by the presence of space charge $(V \Rightarrow 4 / 3 V)$ (see the analysis made by Green $\left.{ }^{8}\right)$ ). The angular divergence $\psi$ for a circular aperture of radius a is found to be

$$
\psi \equiv \frac{a}{3 d} \text { (circular aperture) }
$$

and for a slit aperture of width $2 \mathrm{a}$ we have

$$
\psi \equiv \frac{2}{3} \frac{a}{d} \text { (slit aperture). }
$$

Assuming the fact that the initial angle is convergent, $\theta \cong a / r_{c}$ and making substitutions for $r_{c}$ in Eqs. (46) and (47) we obtain

and

$$
\theta \equiv \frac{5}{8} \frac{a}{d}\left(1-\frac{P}{P_{C}}\right) \quad \text { (circular aperture) }
$$

$$
\theta \equiv \frac{5}{4} \frac{a}{d}\left(1-\frac{P}{P}\right) \quad \text { (sil aperture) }
$$

The final angle, after passing through the second aperture, (assumed to be of the same size as the extraction aperture) is

and

$$
\omega=\theta-\psi=\frac{1}{2} \frac{a}{d}\left(1-1.67 \frac{P}{P_{C}}\right) \quad \text { (circular aperture) }
$$

$$
\omega=\theta-\psi=1.41 \frac{\mathrm{a}}{\mathrm{d}}\left(1-1.47 \frac{\mathrm{P}}{\mathrm{P}_{\mathrm{C}}}\right) \text { (slit aperture). }
$$


These expressions, even though very approximate, illustrate how the angular divergence is affected through changes in the plasma boundary curvature which are effected through changes of the discharge parameters. The forms of the expressions suggest an optimum perveance for minimum angular divergence, i.e.

$$
\begin{aligned}
& P_{\min } \equiv \frac{P_{c}}{1.67} \quad \text { (circular aperture) } \\
& P_{\min } \cong \frac{P_{c}}{1.47} \quad \text { (slit aperture). }
\end{aligned}
$$

Although absolute divergence $(\omega \cong 0)$ may be desirable in order to transport the beam through limited acceptance beam transport systems, this mode of operation is not compatible with maximum resolution where sharp virtual object are desirable. Therefore, it is desirable to operate the source with angular divergence whenever high resolution is required. (Due to thermal velocity spreads of the heavy particles in the plasma, the minimum perveance is never zero and relatively sharp virtual objects exist in practice.)

Several experimental measurements have been made which verify these previous qualitative productions. Figure 11 iliustrates the dependence of angular diverge $w$ on perveance and extraction gap as determined by several investigators $44,54,88$ ).

In addition of a third electrode between the ground and extraction electrodes which is maintained at a negative $V^{-}$potential relative to ground will also alter the final angular divergence. This electrode permits a change in perveance without changing the energy of the ion beam, adds and 
additional controllable optical element in the extraction system and prevents electrons generated by the ion beam and residual background from back gas streaming to the source thus reducing space charge neutralization of the beam. Figure 12 shows schematically a three element circular aperture electrode systenl which as been studied by Cooper et al. ${ }^{53}$ ) by computational analyses. Coupland $e z a .{ }^{54}$ ) have experimentally analyzed a three element extraction system similiar to that shown in fig. 12 and found that the increase in divergence due to the introduction of a third electrode can be expressed as

$$
\left.\Delta \omega=\frac{1}{3} \frac{r_{b}}{d_{1}}\left\{1+\frac{d_{1}}{d_{2}}\left[2-\left(\left|\frac{v^{-}}{v_{+}}\right|+1\right)^{-3 / 4}+\left(\left|\frac{v^{-}}{v_{+}}\right|+1\right)^{3 / 4}\right)\right]\right\}
$$

where $r_{b}$ is the beam diameter through the electrodes, $d_{1}$ is the first gap and $d_{2}$ is the second.

\subsection{EXTRACTION ELECTRODE DESIGN}

Ion optics and extraction electrode optimization have been made considerably easier by the development of sophisticated computer codes which can calculate in a self-consistent manner, ion beam trajectories (including space charge) through real electrode geometries. The program, after arriving at a self consistent solution to Poisson's equation then calculates the current density across the plasma in iterative steps until a minimum variation in density is obtained. The program is attributable to Kirstein and Hornsby ${ }^{55}$ ) and developed further by Bates ${ }^{56}$ ).

Computations have been made by Cooper et al. ${ }^{53}$ ) to optimize the design of the three element circular aperture electrode systems shown in fig. 12. 
Beam optical calculations have also been made with a similiar code by Whealton $e=a^{57,58}$ ). Examples of such calculations are shown in fig. 13. comparisons of beam trajectories, equipotentials and plasma boundaries for ion extraction from slit and circular apertures are made.

Experimentally, Coupland etaz.54) have carefully evaluated a three element circular aperture electrode system similiar to the configuration of fig. 12. The most critical parameter was found to be the ratio of the radius of the extraction aperture $r_{1}$ to the first electrode gap $d$ or $S=r_{1} / d$ with the highest current densities obtained at $S \leq 0.5$. The optimum beam divergence for the system was found to be $\omega= \pm 1.2^{\circ}$. The measured perveance of the system at minimum beam divergence agreed well with values predicted with the simple model based on the Langmuir-Blodgett formula for the spherical eiectrode systen.

As a matter of practical importance in the design of the electrode system the value or $d$ should be chosen so that sparking is minimized and voltage breakdown does not occur. Coupland et al. ${ }^{54}$ ) and Hamilton ${ }^{59}$ ) have shown that the maximum voltage $V_{B}$ that can be applied across a gap $d$ is given by

$$
V_{B} \cong 6 \times 10^{4} d^{1 / 2}[v] \text {. }
$$

In sources ihere condensable vapors are emitted, additional sparking and perhaps voltage breakdowns may result due to deposits on the extraction electrode system.

\subsection{TYPES OF PLASMA DISCHARGE SOURCES}

Several types of plasma ion sources exist which are being used with a variety of accelerators. The sources principally differ in the means of 
producing the discharge or the physical arrangement for extracting the ions from the plasma.

Duopiasmatron Ion Sources - The duoplasmatron ion source, described by Von Ardenne ${ }^{1}$ ) is widely used at accelerator installations, primarily for the production of ion beams from noncorrosive gaseous materials. Many versions of the source have been described in the literature ${ }^{1,60-67}$ ). The characteristics of the source plasma have been determined by Demirkhanov et al. ${ }^{63}$ ), Kistemaker et az. ${ }^{64} \mathrm{~J}$, and Lejeune ${ }^{65}$ ).

A discharge is maintai and between a hot cathode and an anode. A strong magnetic inhomogeneous field ( $j-10 \mathrm{kG}$ ) maintained between an intermediate electrode and the anode concentrates the discharge near the extraction aperture in the anode region by the action of the field. The plasma in the anode region attains densities of the order of $n_{e} \equiv 1 \times 10^{14}$ from which ion beams are extracted. The source is characterized by high efficiency (greater than $80 \%$ for hydrogen) and high current densities.

Although the source is used primarity for noncorrosive gaseous materials, versions have been constructed which can be used with low pressure and corrosive materials. The source of Masic, Warnecke, and Sautter ${ }^{66}$ ) designed for use in an isotope separator is shown in fig. 14. The required feed vapor is introduced in the expansion cup while the primary discharge is sustained with helium or argon. The source of Illgen et az. ${ }^{67}$ ) designed for multiply charged ion production is also shown in fig. 14. The source is fitted with a ring shaped vaporized oven between the intermediate electrode and the anode for processing solid materials. 


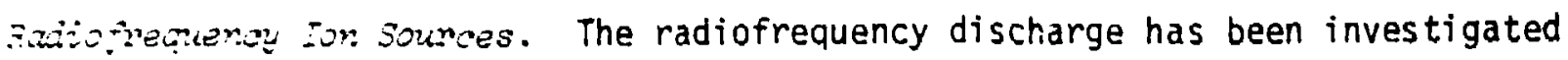
by several experimenters ${ }^{68-72}$ ). The discharge is effected by an rf oscillator with frequencies in the range of 1 to $100 \mathrm{MHz}$ required to excite the discharge. An axial magnetic field is usually employed to direct the discharge and the ions are extracted through a canal in one end of the chamber. The source generally requires an order of magnitude higher gas pressure $\left(10^{-2}\right.$ to $10^{-1}$ Torr $)$ than conventional hot cathode discharge sources. Proton currents of the order of $100 \mathrm{~mA}$ have been obtained in pulsed mode operation ${ }^{72}$ ). The source is generally used for simple gases but versions which can be used to produce beams from more complex gases and solids have been reported ${ }^{69-71}$ ).

Penning Discinarge Ion Sources. The Penning discharge ion source consists of two cathodes placed at the ends of a cylindrical hollow anode. Electrons, produced in the discharge, oscillate between the cathodes and are constrained from moving to the anode cylinder by means of magnetic field directed parallel to the axis of the anode.

Versions of the source exist for which ion extraction is made through an aperture in the wall of the anode (side extraction) or through an aperture in one of the cathodes (end extraction). Some sources employ hot cathodes which emit electrons thermionically to initiate the discharge while others use cold cathodes where electrons are emitted principally by secondary processes. The cathode, in the hot cathode version, may be directly or indirectly heated. An example of a hot cathode Penning source is shown in fig. 15. The source was originally designed for use in a small isotope separator by ivielson ${ }^{27}$ ). A wide variety of materials may be processed in the ion source by external feed of gaseous materials, direct evaporation of solids in either of two overis having a temperature range of 600 to $1200^{\circ} \mathrm{C}$, or by halogenation 
of heated oxides or elemental materials. Typically, ion currents of a few to several hundred $\mu \mathrm{A}$ are produced by a source of this type.

The cold cathode Penning source is used primarily to produce ions from gaseous materials but its range of capability may be extended by direct vaporization, internal systhesis or the use of the sputtering technique. The side extraction version is the principal source used in cyclotrons and is one of the most prolific generators of multiply charged heavy ions in existence.

Holiow Cathode Ion Sources. A hollow cathode ion source, developed by Sidenius for use in electromagnetic isotope separation processes ${ }^{28}$ ), is shown in fig. 16 The hollow cathode ion source rolies on emission of electrons from a thin wall tube which may be heated directly or self-heated to maintain the discharge. The source uses a helically wound tungsten filament to heat the cathode to emitting temperatures. The oven temperature may be varied between 200 and $2000^{\circ} \mathrm{C}$ by regulating its position in the innermost tube of the source. Analyzed beams of $400 \mu \mathrm{A}$ of argon and $150 \mu \mathrm{A}$ of lead have been observed using a $0.5 \mathrm{~mm}$ dia. exit aperture. The magnetic field produced by the cathode heating filament is canceled by the windings of the auxilliary magnet coil.

Freeman Source. The source shown in fig. $1^{-1}$ was developed for use with an electromagnetic isotope separator by Freeman and therefore has a capability of producing a wide variety of ion beams ${ }^{25}$ ). The controllable temperature range of the source oven lies between 550 and $1100^{\circ} \mathrm{C}$. The source oven is also equipped with an inlet for introducing halogenating agents such as $\mathrm{CCl}_{4}$ or $\mathrm{ClF}_{3}$. Ion beams of the platinum or jalladium groups of metals may also be produced by mounting a sputtering probe made of the material in the rear 
of the discharge chamber. The cathode is a tantalum or tungsten rod with a flat emitting surface, mounted $3 \mathrm{~mm}$ behind a slit aperture $\left(1.5 \times 42 \mathrm{~mm}^{2}\right)$. An auxilliary magnetic field of $0-150 \mathrm{G}$ is maintained parallel to the axis of the cathode. The source produces analyzed currents up to a few $\mathrm{mA}$ of most elemental materials.

Magnetron Ion Sources. The magnetron source developed for use in mass spectrometry by Perovic ${ }^{30}$ ) and Cobic et al. ${ }^{31}$ ) is similar in principle to the Freeman source. The primary difference is that the magnetron source filament is coaxial with the discharge chamber and auxiliary magnetic field. The magnetron discharge exhibits an abrupt cutoff at magnetic field strengths of a few hundred Gauss. Ion beams of metals may be produced by biasing a metal probe, made of the material of interest, negative with respect to discharge chamber or by coating the cathode with the material to be vaporized. The source has a slit extraction aperture of $2 \times 50 \mathrm{~mm}^{2}$ and produces ion currents of gases up to a few $\mathrm{mA}$.

Calutron Type Sources. The calutron source is a side extraction, hot cathode source with a slit extraction aperture and was originally designed to operate within the main magnetic field volume of the large scale calutron isotope separators ${ }^{29}$ ). Several smaller versions of the source have been designed and constructed for use outside the main magnetic field and therefore utilize smail auxilliary magnets to direct the discharge ${ }^{73}$ ). The discharge is effected by a hot filament located at one end of the discharge chamber. The source is very versatile and may be used with gases, elemental and molecular solids or internal chemical synthesis. The controllable temperature 

An axial extraction geometry source designed and developed by Alton ${ }^{76}$ ) shown in fig. 20 , is equipped with a sputter probe and vaporization oven and thus can be used either as a sputter source or conventional oven source. The source is equipped with a permanent magnet for producing a transverse magnetic field $(\leq 350 \mathrm{G})$ and $c$ an be operated with or without the auxilliary field. Polarity reversal permits operation as a high intensity negative ion source when cesium is used in the reservoir. The source produces beams of positive ions of a few to a few hundred uA depending on the particular element.

\section{SURFACE IONIZATION SOURCES}

The surface ionization phenomenon offers a means of efficiently producing ion beams of several elements. Such sources are characteristically very efficient, simple in construction and easy to operate. Sources have been constructed for the production of ion beams from the alkali, alkali earth, and the rare arth metals. The mechanism for ionization depends on the difference between the work function, $W$, of a heated metal such as tungsten and the ionization potential, $\phi$, of the element in question. The ratio of positive ions, $n_{+}$, to neutral atoms, $n_{0}$, leaving the heated surface is giver by the Langmuir-Saha equation

$$
\frac{n_{+}}{n_{0}}=\left(\frac{1-R_{+}}{1-R_{0}}\right) \frac{g_{+}}{g_{0}} e^{\left(\frac{W-\phi}{k T}\right)}
$$

where $R_{+}$and $R_{0}$ are the reflection coefficients of the positive and neutral particles at the surface, $g_{+}$and $g_{0}$ are statistical weighting factors, $T$ is the absolute temperature and $k$ is Boltzmann's constant. The optimum ionization 
efficiencies are obtained for high work function materials and low ionization potential atomic species. Two of the surface ionization sources of Daley et az. ${ }^{77,78}$ ) are shown in fig. 21. The metal vapor is diffused through a heated porous tungsten ionizer which is subjected to a constant stream of oxygen to raise the work function to approximately $6 \mathrm{eV}$.

Many metallic ions may be produced by heating the metal oxide or halide to a very high temperature in a high work function crucible. The ion source of Johnson et $a 2 .{ }^{79}$ ) is shown in fig. 22. The source functions by heating a tungsten crucible containing one of the halides of the rare earth r tals to approximately $2800^{\circ} \mathrm{C}$. Thermal dissociation of the halide reieases elemental rare earth atoms which make many collisions with the cucible walls before being emitted. The source has been lised to generate a wide variety of rare earth species with material utilization efficiencies greater than $70 \%$ recorded for europium and samarium.

\section{OTHER METHODS OF HEAVY ION PRODUCTION}

In the previous sections, we have confined ourselves tc discussions of widely used and more conventional types of heavy ion sources. However, it should be pointed out that there are other advancing technologies which should be briefly mentioned here. Specifically, the use of high power lasers, the phenomenon of electron cyclotron resonance (ECR), electron bombardment (EBIS), and microwave power in the production of heavy ion beams are being used by a few groups.

Laser Ion Sources. Although the technique of ionization by high density laser beam interaction with vaporous materials appears to be very attractive, it has been used very sparingly in ion source applications such as reported recently Dy Goldhar et az. ${ }^{80}$ ). 
The technique is appealing in that it offers potentially, a means of differentially selecting the desired species for ionization. However, there are no lasers available today which have sufficient power in the wavelength region required for efficient and direct ionization of mos $t$ elemental materials. Therefore, multiple photon interactions are necessary for the excitation and ionization of a particular atom which requires an extremely high photon density in the interaction volume.

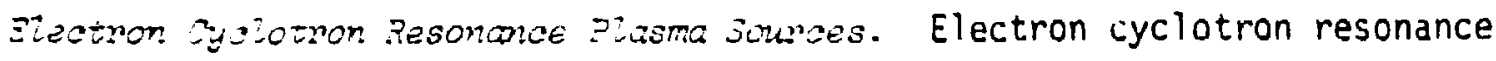
has been very successfully used by Geller $=a i^{81}$ ) as a means of generating multiply charged heavy ions. The technique has not been applied, to our knowledge, for the specific generation of low charge state ions. However, the concept is particularly appealing in that the lifetime of such a source would be very lang.

Electron Impact Ionization Eourses. Electron impact ionization sources (EBIS) are being used by groups in Germany, France, and Russia for the production of very high charge state ions. The technique is attractive only for the production of multiply charged ions and therefore is not appropriate for discussion here. The reader is referred to articles by Donets ${ }^{82}$ ), Arianier and Goldstein ${ }^{83}$ ), Clausnitzer et $a i .{ }^{84}$ ), and Becker and $k ?$ ein ${ }^{85}$ ), for specific details about the apparatus and the techniques.

Microwave Ion Sources. Sakudo et al. ${ }^{86,87}$ ) have developed a multiple aperture ion source for fusion reactor related research and a slit type source suitable for use with ion implantation device or electromegnetic isotopes separators which uses microwave power for plasma generaticn. A schematical representation 
of the slit type source is shown in fig. 23 . The discharge is initiated and sustained by microwave induced excitation and ionization of the gaseous feed material. The oscillatory frequency of the microwave generator is $2.45 \mathrm{GHz}$. Wave guide techniques are used to efficiently transmit several hundred watts of microwave power to the discharge volume which is effective in producing a highly ionized plasma. The discharge volume is designed to be compatible with ion extraction from slit apertures. Analyzed beams of P+ of $10 \mathrm{~mA}$ have been observed from an exit aperture of $2 \times 40 \mathrm{~mm}^{2}$. This technique appears to be very promising, especially for gaseous feed materials, but requires specific knowledge and experience in microwave transmission and coupling techniques in order to efficiently transmit hundreds of watts of power to the ion source discharge volume. The source, because of the nature of the plasma generation technique, should have a very long lifetime unless the exposed dielectric components degrade due to exposure to discharge deposits and chemically corrosive materials.

\section{Conclusions}

The intent of the present article has been to review in a limited sense the more commonly used types of heavy ion sources suitable for low energy accelerator use. Particular emphasis has been placed on hot cathode plasma discharge sources and their technology because of their wide range of ion species capabilities. Because of the tremendous amounts of technological information concerning the many types and varities of heavy ion sources described in the literature, precludes a comprehensive review of the subject. The reader is, therefore, encouraged to consult the referenced literature for detailed information concerning particular ion sources and their associated technologies. 


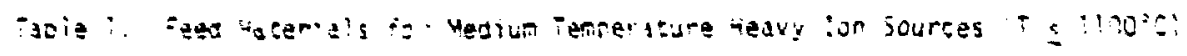

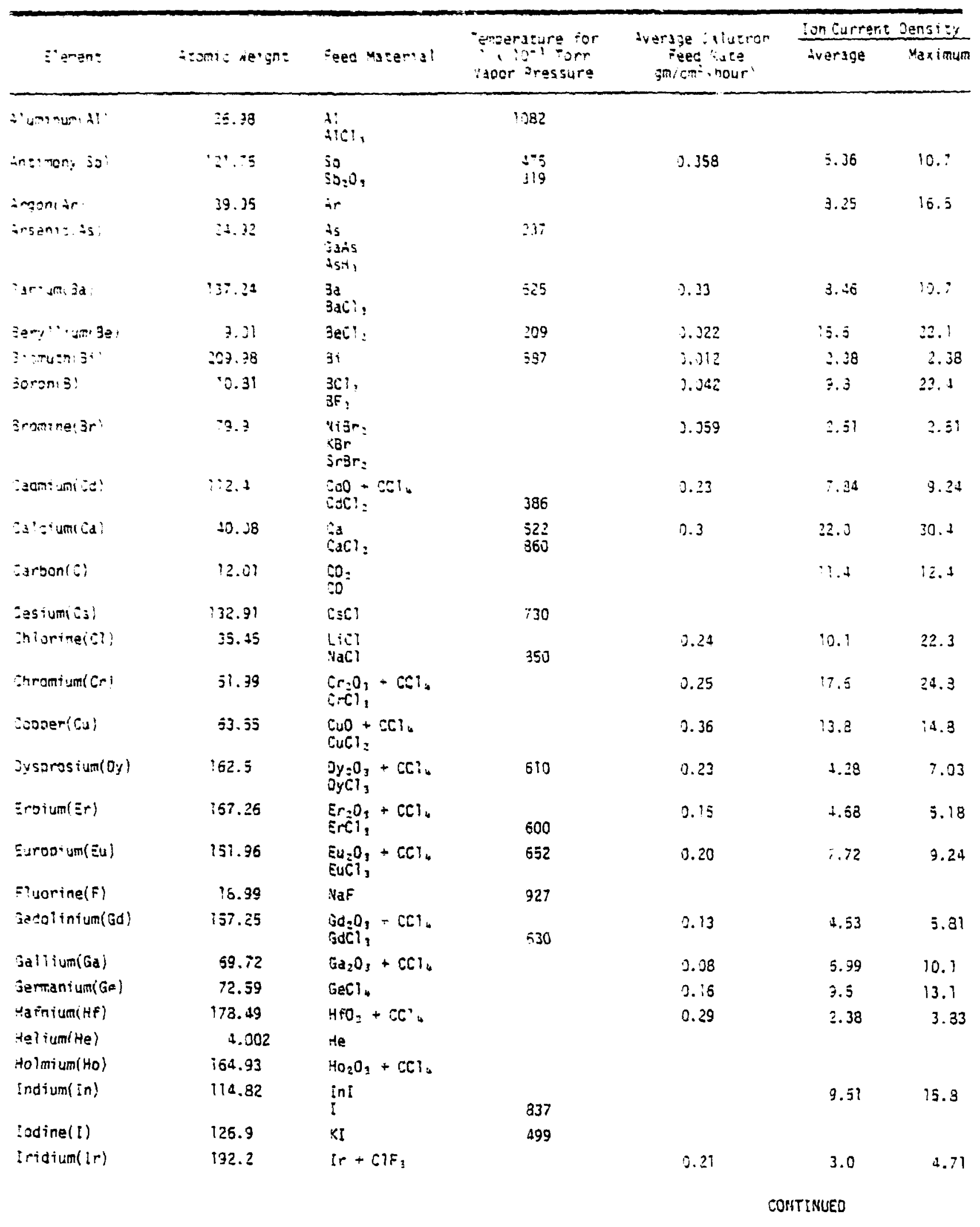


iable 1 (CONTINUED)

\begin{tabular}{|c|c|c|c|c|c|c|}
\hline \multirow[b]{2}{*}{ Fl amente } & \multirow[b]{2}{*}{ ftom: detght } & \multirow[b]{2}{*}{ Feed Materid } & \multirow{2}{*}{$\begin{array}{l}\text { racure for } \\
1.10^{-1} \text { Forr } \\
\text { leagr Pressure }\end{array}$} & \multirow{2}{*}{$\begin{array}{c}\text { Average falutron } \\
\text { feod Rate } \\
\text { 'gm/cm -hourl }\end{array}$} & \multicolumn{2}{|c|}{ :on Currene Density } \\
\hline & & & & & Average & Maximum \\
\hline (ron $(\mathrm{Fat})$ & 55.95 & Fo:l: & 428 & 0.56 & 20.0 & 25.7 \\
\hline kryotan $(k r)$ & 33.3 & & & & & \\
\hline Lanenanumi La) & 138.91 & $\begin{array}{l}\mathrm{La}: 0, \cdot 6 \mathrm{I}_{4} \\
\mathrm{LaCl}\end{array}$ & 351 & 0.129 & $\therefore .06$ & 5.35 \\
\hline Lezd(Pb) & 207.2 & $P b C l:$ & 525 & 0.27 & 4.28 & 5.37 \\
\hline Li inium(L1) & 5.94 & LiCl & $5 i g$ & 2.079 & 32.5 & $? 2.9$ \\
\hline Lutetium(Lu) & 78.27 & 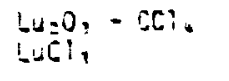 & & 0.17 & 3.79 & 3.47 \\
\hline "agnes ium( $4 \mathrm{cg})$ & 24.31 & $4 g$ & 37 & 0.19 & 30.3 & $38 .:$ \\
\hline Manganese( Mn ) & 34,34 & $y_{n}$ & 337 & & & \\
\hline Mercury ( $\mathrm{Hg}$ ) & 200.59 & $\begin{array}{l}\text { HgS } \\
\text { HgF: }\end{array}$ & & 0.1043 & 0.73 & 9.73 \\
\hline Molybdenum(.,40) & 35.94 & $400,+601$ & & 0.22 & 3.1 & 11.3 \\
\hline Neocymium\{No\} & 144.24 & $40_{2} O_{1}-[C]_{2}$ & & 0.19 & 4.3 & 5.39 \\
\hline $\operatorname{rean}(\mathrm{Ye})$ & 20.129 & $\mathrm{Ne}$ & & & & \\
\hline Nickel(Ni) & $58 . ? 1$ & $\mathrm{NiCl}=$ & 491 & 0.21 & 14.0 & 21.9 \\
\hline$y i$ trogen $(M)$ & IH.C & $y_{2}$ & & & & \\
\hline Osmiumiosi & 190.2 & $\begin{array}{l}\mathrm{OsO}_{4} \\
\mathrm{OS}+\mathrm{O}_{2}\end{array}$ & & & 2.01 & 2.31 \\
\hline Jxygen $(0)$ & $15.3: 3$ & $0:$ & & & 3.21 & 9.24 \\
\hline P!l ladium(Pd) & i06.t & $P A-C 1 F$, & & & 1.98 & 3.59 \\
\hline Platinum $(P t)$ & 195.05 & $s_{t}+C l F_{1}$ & & & 2.3 & 3.96 \\
\hline Phoschorus(D) & 30.97 & $\begin{array}{l}P_{3} \\
P H_{1} \\
P\end{array}$ & & & & \\
\hline Potassium(k) & 39.1 & $\mathrm{~K}_{2} \mathrm{CO}_{3}$ & & & 10.3 & 38.3 \\
\hline Praseodymium(Pr) & $: 20.91$ & $\mathrm{Fr}: \mathrm{O}_{2}+\mathrm{CCl}_{4}$ & & & & \\
\hline Rhen ium(Re) & 36.2 & $\mathrm{Re} \div \mathrm{O}_{2}$ & & 0.27 & 3.53 & 5.28 \\
\hline Rhodium(Rh) & 02.3 & $R h+C I F_{3}$ & & & & \\
\hline Rubidiun(Rd) & 35.47 & $\begin{array}{l}\mathrm{Rb}_{2} \mathrm{CO}_{2} \\
\mathrm{RBCl}\end{array}$ & 555 & 0.07 & 10.2 & 16.3 \\
\hline Putsen ium(Ru) & 101.07 & RuF & 31 & 0.12 & 3.61 & 3.71 \\
\hline Sama rium(Sm) & 150.4 & $\begin{array}{l}5 m_{6} 0_{3}+\mathrm{CC}_{4} \\
\mathrm{Sm}\}_{3}\end{array}$ & 667 & 0.2 & 3.8 & $\Xi .58$ \\
\hline Scandium (Sc) & $44.96^{\circ}$ & $\begin{array}{l}\mathrm{SC}_{2} \mathrm{O}_{3}+\mathrm{CCl}_{4} \\
\mathrm{SCCl}\end{array}$ & 677 & & & \\
\hline SeleniumiSel & 73.26 & $\begin{array}{l}3 e O_{2} \\
\mathrm{CdSe} \\
\mathrm{Se}\end{array}$ & $\begin{array}{l}588 \\
199\end{array}$ & 0.27 & 5.33 & $7 . i$ \\
\hline silicon(si) & $2 \varepsilon . .9$ & $\begin{array}{l}\text { sis } \\
\operatorname{sici}_{4}\end{array}$ & & 0.083 & 5.53 & 8.58 \\
\hline Sitver $(A g)$ & 107.37 & $\underset{\mathrm{Ag}}{\mathrm{AgCl}}$ & $\begin{array}{l}593 \\
922\end{array}$ & 0.42 & 11.2 & $: 7.5$ \\
\hline Sudtium(Na) & 22.99 & $\begin{array}{l}\mathrm{YaCl} \\
\mathrm{YaBr}\end{array}$ & $\begin{array}{l}350 \\
791\end{array}$ & & & \\
\hline
\end{tabular}

CONTINUED 
- to ie : GNTange:

\begin{tabular}{|c|c|c|c|c|c|c|}
\hline \multirow[b]{2}{*}{ Èmen: } & \multirow[b]{2}{*}{ isomic relgh: } & \multirow[b]{2}{*}{ Eeed Macerisi } & \multirow{2}{*}{ 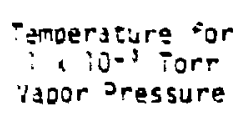 } & \multirow{2}{*}{$\begin{array}{c}\text { iverage Giufron } \\
\text { Feed Race } \\
g m / c m^{-}-\text {nour }\end{array}$} & \multicolumn{2}{|c|}{ Ion Eurrent Density } \\
\hline & & & & & Iverage & Maximum \\
\hline E-ranclumisrl & 97.5 & $\begin{array}{l}3 r \\
\text { sect: }\end{array}$ & $\begin{array}{l}465 \\
356\end{array}$ & 3.24 & 10.8 & 13.2 \\
\hline jw" tspisi & 32.35 & $\begin{array}{l}5 \pm 51= \\
C 25 \\
C S 2\end{array}$ & 510 & 3.25 & 9.2 & 14.0 \\
\hline - zasa lumtia! & 30.35 & $\begin{array}{l}\mathrm{Ta}_{2} \mathrm{O}_{3} \\
\mathrm{TaCl}_{3}\end{array}$ & & 0.30 & 4,47 & 7.71 \\
\hline 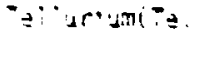 & $: 27.5$ & $\begin{array}{l}i e \\
\text { idte }\end{array}$ & 505 & 3.25 & $5 .: 8$ & 0.32 \\
\hline "aroviumílisi & 158.92 & $\begin{array}{l}T b C 1_{3} \\
T b, 0,+C C 1_{2}\end{array}$ & & & & \\
\hline hallium(ii) & 324.37 & $\begin{array}{l}\text { i1 } \\
\text { i's }\end{array}$ & 530 & 0.30 & 3.03 & 3.57 \\
\hline Tingrium(Th) & 232.04 & $\begin{array}{l}\text { ThCl: } \\
\text { ThO }=\text { - CCl: }\end{array}$ & & & & \\
\hline Thu liumitim) & 163.93 & $\operatorname{im}_{i} \mathrm{O}_{3}+\mathrm{CO} \mathrm{C}_{3}$ & & & & \\
\hline$=\ln (5 n)$ & 118.09 & $\begin{array}{l}\text { jns } \\
\text { SnCt }_{4}\end{array}$ & & 3.29 & 7.16 & 11.3 \\
\hline -i:anium(:i) & $\therefore .3$ & $\mathrm{TiCl}_{4}+\mathrm{CCl}_{4}$ & & 0.12 & 11.1 & 13.0 \\
\hline -ungsten( $(d)$ & 133.95 & $\begin{array}{l}\mathrm{AO}_{3}+\mathrm{CCl} \mathrm{Cl}_{5} \\
\mathrm{NCl}\end{array}$ & & 0.12 & 4.05 & 5.49 \\
\hline -ranium(U) & 238.02 & $\begin{array}{l}\mathrm{UCl}_{2} \\
\mathrm{OO}_{2}\end{array}$ & & & 12.28 & 13.3 \\
\hline -anadium( $y)$ & 50.34 & $V F_{3}$ & 587 & 9.31 & 11.1 & 12.9 \\
\hline (Enonixe) & 131.3 & $\mathrm{xe}$ & & & & 12.4 \\
\hline$y=$ teroium( $(v)$ & 173.04 & $\begin{array}{l}\left.Y b=O_{3}+C C\right]_{4} \\
Y b C I_{3}\end{array}$ & 614 & & & \\
\hline $1: \pm r i u m(Y)$ & 38.9 & $\begin{array}{l}Y_{2} O_{3}+C C I_{4} \\
Y C l_{3}\end{array}$ & 613 & & & \\
\hline Zinc(Zn) & 65.37 & $\begin{array}{l}\ln _{n} \\
\text { ins }\end{array}$ & $\begin{array}{l}292 \\
774\end{array}$ & 0.21 & 16.7 & 29.4 \\
\hline Zieconium(?r) & 91.22 & $\underset{\mathrm{ZrO}_{2}}{\mathrm{ZrI}_{4}}+\mathrm{CCl}_{4}$ & 93 & 0.24 & 7.48 & 3.96 \\
\hline
\end{tabular}


References

1) M. Von Ardenne, Tabellen der Elektronenphysik, Ionenphysik und Ubermikroskopie (VEB, Deutscher Verlag der Wissenschaftrer, Berlin, 1956).

2) M. D. Gabovich, Instr. and Exp. Techn. 3 (1967) 477 .

3) M. D. Gabovich, Physics and Techniques of Plasma Ion Sources (Atomprint, Moscow, 1972), in Russian.

4) J. H. Freemen and G. Sidenius, Proc., Vienna (1972) p. 724; also Nucl. and Meth. 107 (1973) 477 .

5) G. Dearnley, J. H. Freeman, R. S. Nelson and J. Stephen, Ion Implantation (North-Holland, Ansterdam, 1973).

6) R. G. Wilson and G. R. Brewer, Ion Beams with Application to Ion Implantation (John Wiley and Sons, New York, 1973).

7) G. D. Alton, Proc. Third Conf. on Application of Small Accelerators, II (1974) 11.

8) T. S. Green, P.ep. Progr. Phys. 37 (1974) 1257.

5) G. Sidenius, Nucl. Instr. and Meth. 151 (1978) 349.

10) Proc. Sec. Int. Conf. on Ion Sources, Vienna, 1972 (SGAE, Vienna, 1972).

11) Proc. Symp. on Ion Sources and Application Technology, Kyoto, 1977 (The Institute of Electrical Engineers of Japan, 1974).

12) Proc. Symp. on Ion Sources and Formation of Ion Beams, Brookhaven, 1971 (BNL, New York, 1971).

13) Froc. Sec. Symp. an Ion Sources and Formation of Ion Beams, Berkeley, 1974 (LBL, California, 1974).

14) Proc. Int. Conf. Multiply Charged Heavy Ion Sources and Accelerator Systems, Gatl inburg, 1971 IEEE Trans. Nucl. Sci. 19 (1972) no. 2. 
15) Proc. Int. Conf, on Heavy Ion Sources, Gatlinburg, 1975, IEEE Trans. Nucl. Sri. 23 (1976) no. 2.

16) Proc. Electromagnetic Separation of Radioactive Isotopes, Vienna, 1960 (Springer Verlag, Vienna, 1961).

17) Proc. Electromagnetic Isotope Separators and Their Applications, Aarhus, 1965, Nucl. Instr. and Meth. 38 (1965) 1.

18) Proc. Int. Conf. on Electromagnetic Isotope Separators and the Techniques of Their Applications, Marburg, 1970, Forschungsbericht K70-28, Germany (1970).

19) Proc. 8th Int. EMIS Conf. on Low Energy Ion Accelerators and Mass Separators, Sköved, 1973 (Institute of Physics, Gothenburg, 1973).

20) Proc. IXth Conf. on Electromagnetic Isotope Separators and Related Ion Accelerators, Kiryat Anavim, Nucl. Instr. and Meth. 139 (1976) 1.

21) Proc. European Conf. on Ion Implantation Reading, Engl and, (1970).

22) D. D. Townsend, J. C. Kelly and N. E. W. Hartley, Ion Implantation, Sputtering and Their Applications (Academic Press, London, 1976).

23) Proc. Int. Conf. on Low Energy Ion Beams, Salford, 1977 (The Institute of Physics, Conf. Series no. 38, London, 1978).

24) Electromagnetic Isotopes Separations (ORNL Manual).

25) U. H. Freelnan, G. A. Gard, and Ho Temple, AERE Report 6758 (1971).

26) J. F. Freeman and G. Sidenius, Nucl. Instr. and Meth. 107 (1973) 477.

27) K. O. Nielson, Nucl. Instr. and Meth. 1 (1957) 289.

28) G. Sidenius, Proc. Intern. Conf. on Electromagenetic Isotope Separators, Marburg, F. R. Germany (1970) 423. 
29) Separation of Isotopes in Calutron Units, ed. H. H. Savage, Nuclear Energy Series, 1951.

30) B. Perovic, Proc. Third Intern. Conf. on Ion. Phen. in Gases (1957) 813.

31) B. Cobic, D. Tosic, and B. Perovic, Nucl. Instr. and Meth. 24 (1963) 358.

32) J. H. Freeman, Nucl. Instr. and Meth. 22 (1963) 300 .

33) V. P. Boehin, 8. E. Gavrilov, and V. S. Lolotarev, Isotopenpraxis 7 (6) (1971) 232.

34) E. W. Newinan, W. A. Bell, Jr., W. C. Davis, L. O. Love, H. K. Prater, K. A. Spainhour, J. G. Tracy, and A. M. Veach, Nucl. Instr. and leth. 139 (1976) 87.

35) D. Bohm, E. H. S. Burhop, and H. S. W. Massey in Characteristics of Electrical Discharges in Gases, eds. A. Guthrie and R. K. Wakerling, McGraw Hill, New York (1949).

36) 0. Almen and K. O. Nielsen, Nucl. Inst. and Meth. 1 (1957) 302.

37) I. Chavet, Thesis, Iniversity of Paris, (1965).

38) I. Langmuir, Phys. Rev. 2, (1913) 450.

39) I. Langmuir, Phys. Rev. 33 (1929) 954.

40) P. Sigmund, Phys. Rev. 184 (1969) 383.

41) H. H. Anderson and H. L. Bay, in Surface Interaction, Sputtering and P.elated Phenomena, eds. P. Behrish, H. Heiland, H. Poschanrieder, P. Staib and H. Verbeek (Gordon Breach, London, 1973).

42) W. L. Rautenbach, Nucl. Inst. and Meth. 12 (1961) 196.

43) E. R. Harrison and H. B. Thompson, Proc. Phys. Soc. 72 (1959) 214.

44) I. Chavet and R. Bernas, Nucl. Inst. and Meth. 47 (1967) 77.

45) T. S. Green, Production of Negative Deuterium Ion Eeams, CuTham Laboratory Intern. Group Memorandum (1971). 
45) E. Thompson, Particle Accel. $\underline{4},(1072) 60$.

47) I. Langmuir and K. R. Blodgett, Phys. Rev. 22 (1923) 347.

48) I. Langmuir and K. R. Bl odgett, Phys. Rev. 24 (1924) 49.

49) J. R. Pierce, 1940 J. Appl. Phys. 11548.

50) G. R. Brewer, IEEE Spectrum 2. (1965) 65, Physics and Technology of Ion Motors, ed F. E. Marble and J. Surugue (London: Eordon and Breach, 1966) p. 255.

51) I. Langmuir and K. Compton, Rev. Mod. Phy's. 13 (1931) 191.

52) C. J. Davisson and C. J. Calbick, Phys. Rev. 38, (1931) 585.

53) H. S. Cooper, K. H. Berkner, and R. V. Pyle, Nucl. Fusion 12 (1972) 163, 2nd Int. Conf. Ion Sources, Vienna (1972) p. 264.

54) J. R. Coupland, T. S. Green, D. P. Hammond, and A. C. Riviere, Rev. Sci. Instrum. 44 (1973) 1258.

55) P. T. Kirstein and J. S. Hornsby, IEEE Trans. Electron Devices ED-11 (1964) 196.

56) D G. Bates, 1966 CLM-P. 53 CuTham Laboratory

57) J. H. Whealton, R. W. McGaffey, E. F. Jaeger, Appl. Phys. Lett. $\underline{36}$ (1980) 91.

58) J. H. Whealton, (these proceedings).

59) G. W. Mamilton, Symp. Ion Sources, Brookhaven BNL 50310 (1971) 171.

60) C. D. Moak, H. E. Banta, J. N. Thurston, J. W. Johnson, and R. F. King, Rev. Sci. Instr. 30 (1959) 694.

61) H. Fröhtiche, Nukleonic 1 (1959) 183.

52) H. Winter, Proc. Intern, Conf. on Electromagnetic Isotope Separators, Marburg, F. R. Germany (1970) 447. 
63) R. A, Demirkhanov, H. Fröliche, V. V. Kursanov, and T. T. Gutkin, BNL Peport 767 (1962) 218.

64) J. Kistemaker, P. K. Rol, and J. Politiek, Nucl. Instr. and Meth. $\underline{38}$ (1965) 1.

65) C. Lejeune, Nucl. Instr. and Meth. 116 (1974) 417.

66) R. Masic, R. J. Warnecke, and J. M. Sautter, Nucl. Instr. and Meth. 71 (1969) 339.

67) J. Illigen, R. K. Kirchner, and J. Schulte in den Baumen, IEEE Trans. on Nuc1. Sci. 19 (1971) 35 .

68) P. C. Thoneman, Nature 158 (1964) 61.

69) V. F. Kozlov, V. Y. Kolot, and Sun-Chzhei-tszin PTE, NNo. 6 (1962) 116.

70) V. F. Kozlov, V. L. Marchenko, and Y. M. Fogel, PTE, №. 1 (1961) 25.

71) R. H. Dawton, in Electromagnetically Enriched Isotopes and Mass Spectrometry, London (1965),

72) E. Regenstreif, Le Synchrotron a Protons du Cern, Geneva (1959) ch. 5.

73) Oak Ridge National Laboratory $130^{\circ}$ Sector Electromagnetic Isotope Separator (unpublished).

74) R. Bernas and 0. Nier, Rev. Sci. Instr. 19 (1943) 895.

75) K. J. Hi 11 and R. S. Nelson, Nucl. Instr. and Meth. 38 (1965) 15.

76) G. D. Alton, IEEE Trans. Mucl. Sci. NS-26, No. 3 (1979) 3708.

77) H. L. Daley, J. Perel, and R. H. Vernon, Rev. Sci. Instr. 37 (1966) 473.

78) H. L. Daley and J. Perel, Rev. Sci. Instr. 42 (1971) 1324.

79) P. G. Johnson, A. Bolson, and C. M. Henderson, Nucl. Instr. and Meth. 106 (1973) 83.

80! J. Goldhar, R. Mariella, Jr., A. Javan, Appl. Phys. Lett. 29 (1976) 96. 
81) R. Geller, IEEE Trans. Nuc?. Sci. NS-23, No. 2 (1976) 904.

82) F. D. Donets, IEEE Trans. Mucl. Sci. NS-23, No. ? (1976) 879.

83) J. Ariamer and C. Foldstein, IEEE Trans. Nucl. Sci. NS-23, No. 2 (1976) 979.

84) G. Clausnitzer, H. Klinger, A. Muller and E. Saltzborn, IEEE Trans. Mucl. Sci. NS-23, No. 2 (1976) 1027.

85) p. Becker and 4. Klein, IEEE Trans. Nucl. Sci. NS-23, No. 2 (1976) 1017.

86) N. Sakudo, K. Tokiguchi, H. Koike, and 1. Kanomata, Rev. Sci. Instrum. 48 (1977) 762.

87) N. Sakudo, K. Tokiguchi, H. Koike, and I. Kanamda, Rev. Sci. Instrum. 49 (1978) 940.

88) V. I. Raiko, Kernenergie 10, (1967) 89 (Trans1. Oak Ridge, 1971).

89) W. Walscher, Electromagnetic Isotope Separators And Applications of Enriched Isotopes, ed. J. Koch, (1958) (Amsterdam: North Holland). 
Figure Captions

1. Calutron ion source fluorination system for the platinum-palladium metals $\left(\right.$ ref. $\left.\left.^{34}\right)\right)$.

2. Typical hot cathode plasma discharge ion source geometries.

3. Double layer sheath formation surrounding a biased hot filament.

4. Potential variation near the sheath double layer illustrating the field penetration $\delta$.

5. Schematic of a ribbon plasma discharge of length $Z$ with field penetration $\delta$ at the ends.

6. Theoretical cathode lifetime limited by physical sputtering.

7. Illustration of possible plasma boundary curvatures during ion extraction which may be effected by changes in plasma density or extraction paran irs.
a) Concave meniscus;
b) flat meniscus;
c) convex meniscus;
d) complex curvature which leads to beam aberrations.

8. Magnetically analyzed ion current density data as a function of atomic mass. Ion currents represent maximum values observed for the respective specie. (Calutron data from ref. ${ }^{24}$ ).

9. Ionization cross sections as a function of electron bombarding energy (ref. $\left.{ }^{89}\right)$.

10. Simplified ion optics in the extraction region of a two electrode system.

11. Experimentally determined ion beam angular divergences during extraction. Coupland et $a t .{ }^{54}$ ); curve A - theoretical curve B - experimental angular divergence versus perveance (I constant, $V$ varied); curve $C$ - experimental angular divergence versus perveance ( $V$ constant; I varied).

Chavet-Bernas ${ }^{44}$ ); curve $A$ - experimental angular divergence versus extraction electrode gap. Curve $A$ - xenon ion beam; curve $B$ - argon ion beam. 
Figure Captions (continued)

Raiko ${ }^{88}$ ). Variation of angular divergence with perveance for different extraction electrode gaps.

12. Three electrode ion extraction system.

13. Computational analyses of slit and circular aperture extraction system (Wheal ton $\left.{ }^{57}\right)$ )

14. Heavy ion duoplasmatron sources-Masic et $a z^{66}$ ) and (1/gen et al. ${ }^{67}$ ).

15. Hot cathode Penning discharge source ${ }^{27}$ ).

16. Hollow cathode source ${ }^{28}$ ).

17. Freeman ion source ${ }^{25}$ ).

18. Calutron ion source ${ }^{29}$ ).

19. Sputter source ${ }^{75}$ ).

20. Positive or negative ion source ${ }^{76}$ ).

21. Surface ionization sources ${ }^{77,78}$ ).

22. High temperature surface ionization source ${ }^{79}$ ).

23. Microwave generated plasma discharge source ${ }^{87}$ ). 
OIINL-DWG $72-99 i$,

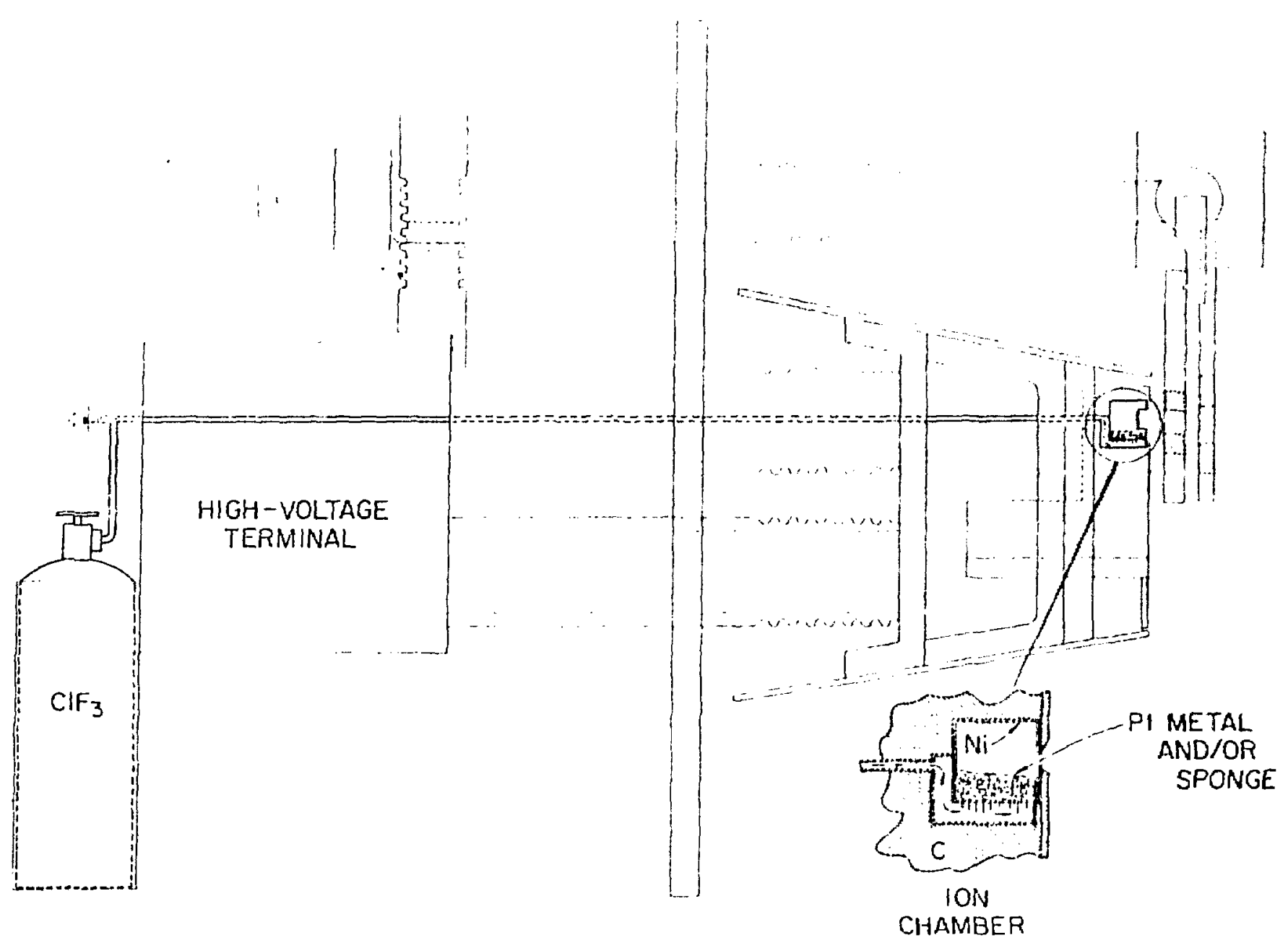

Fig. 1 
ORNL CWE BO.1351EA

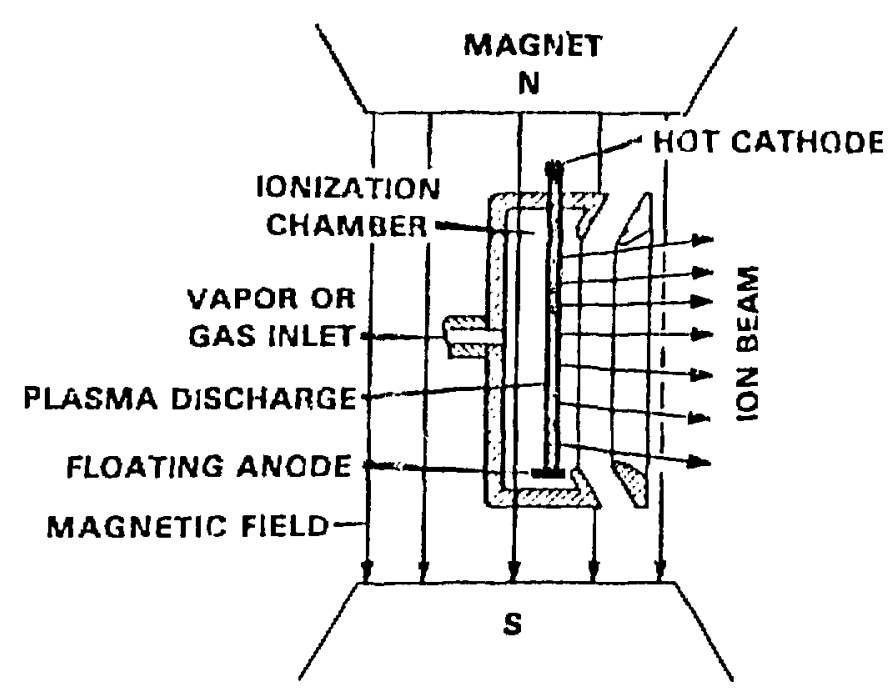

SIDE EXTRACTION ION SOURCE CONFIGURATION

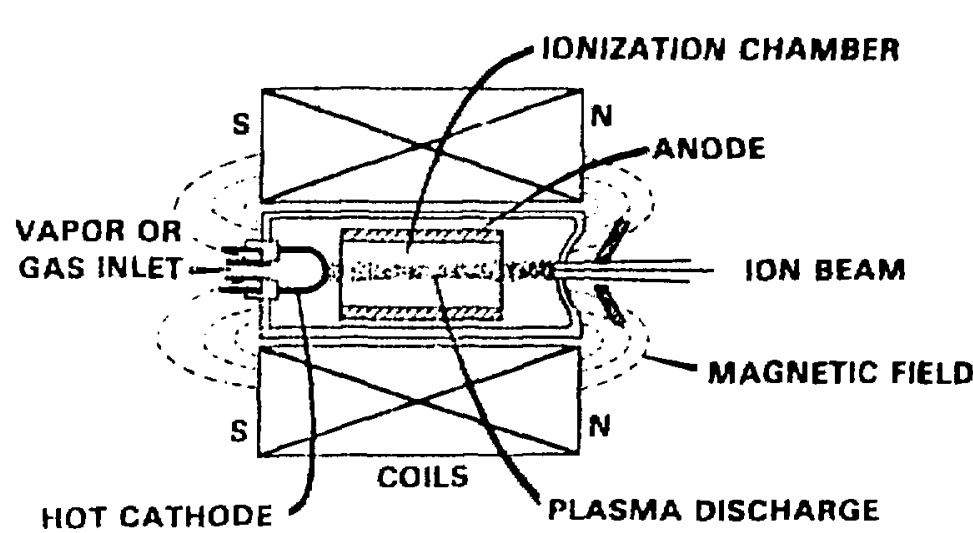

END EXTRACTION ION SOURCE CONFIGUHATION 
ORNL-DWG 80-13519A

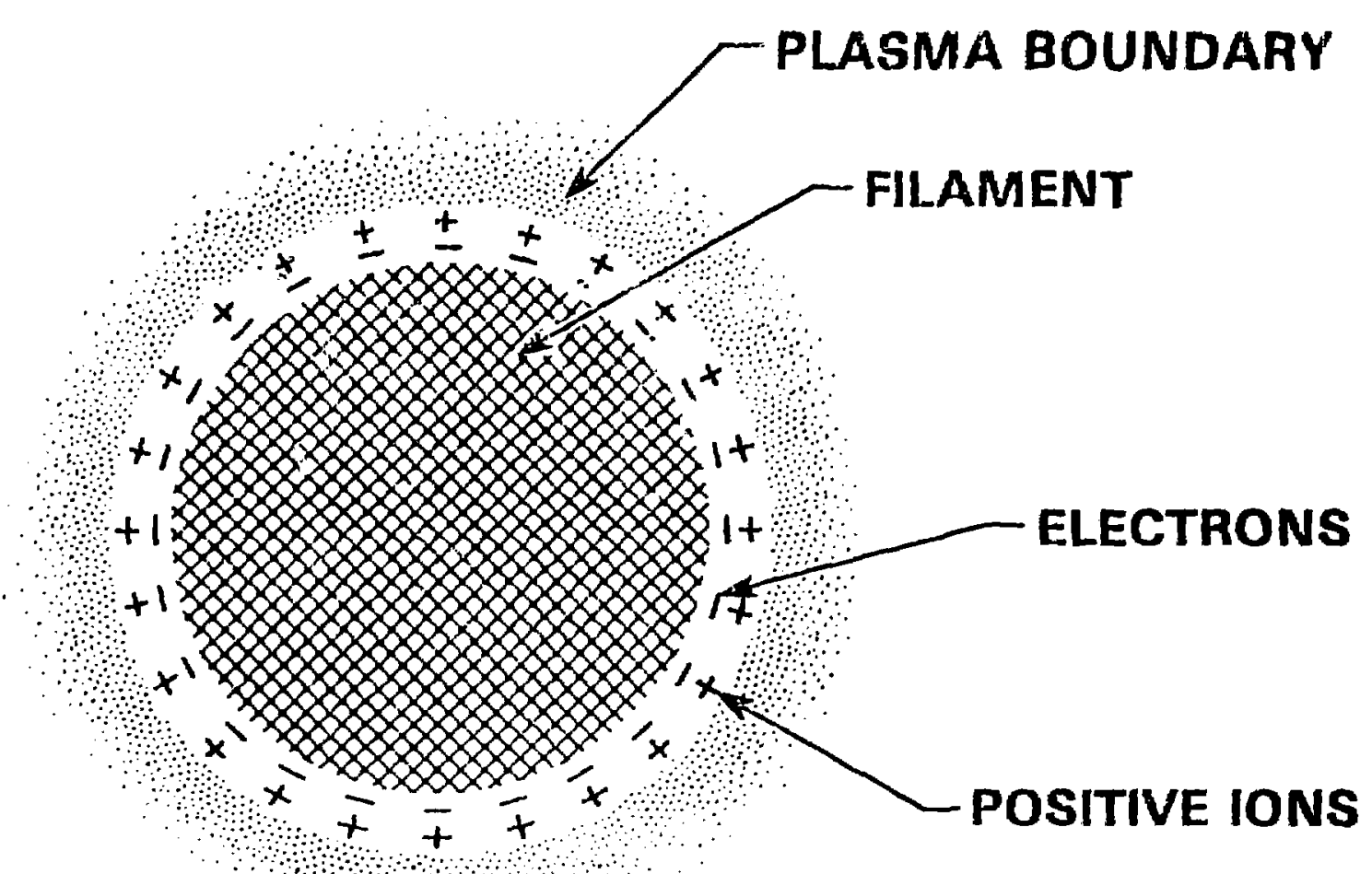




\section{OANL-DWG 80-13528A}

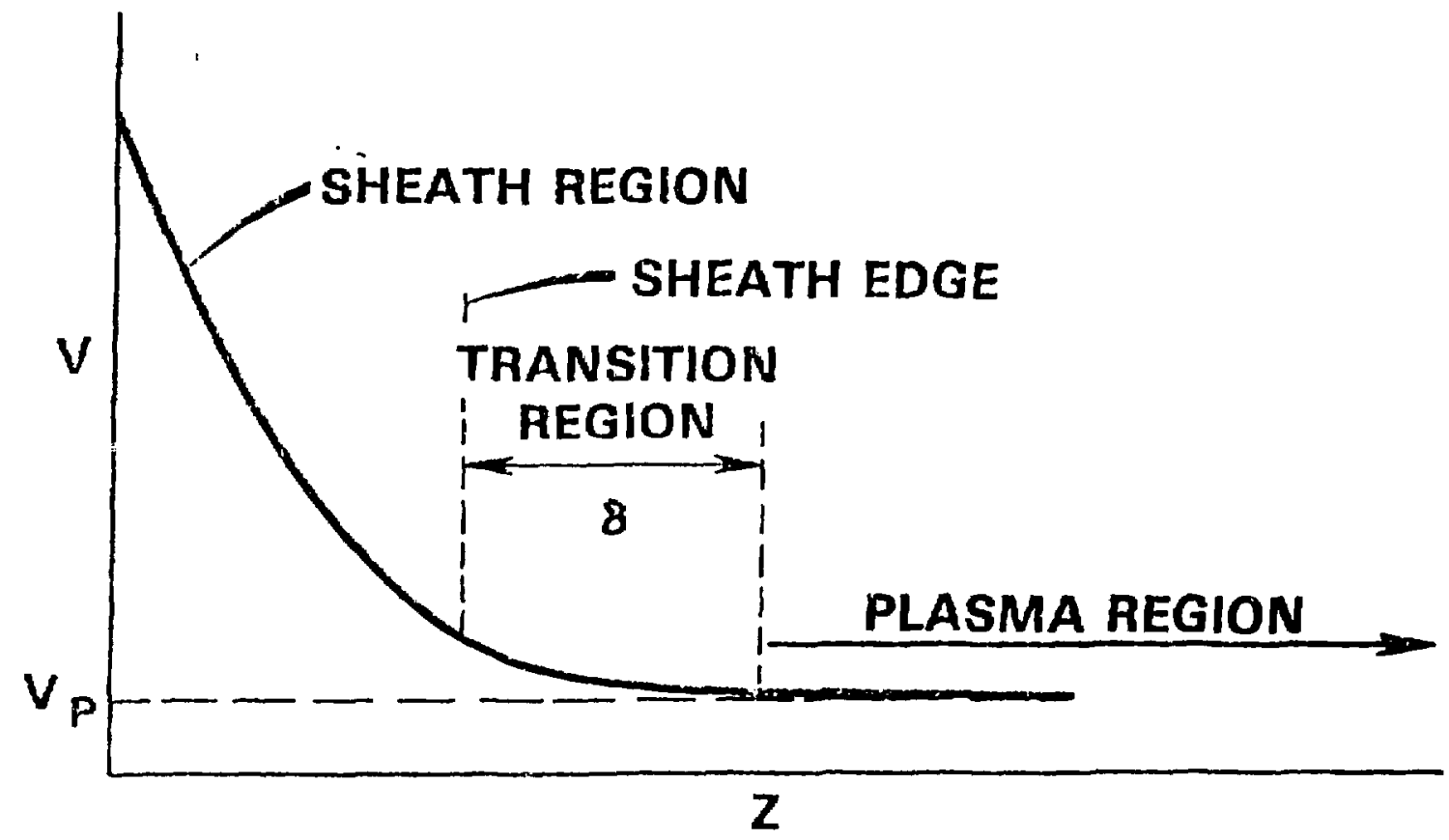

Fig. 4 
ORNL-DWG BO-13517A

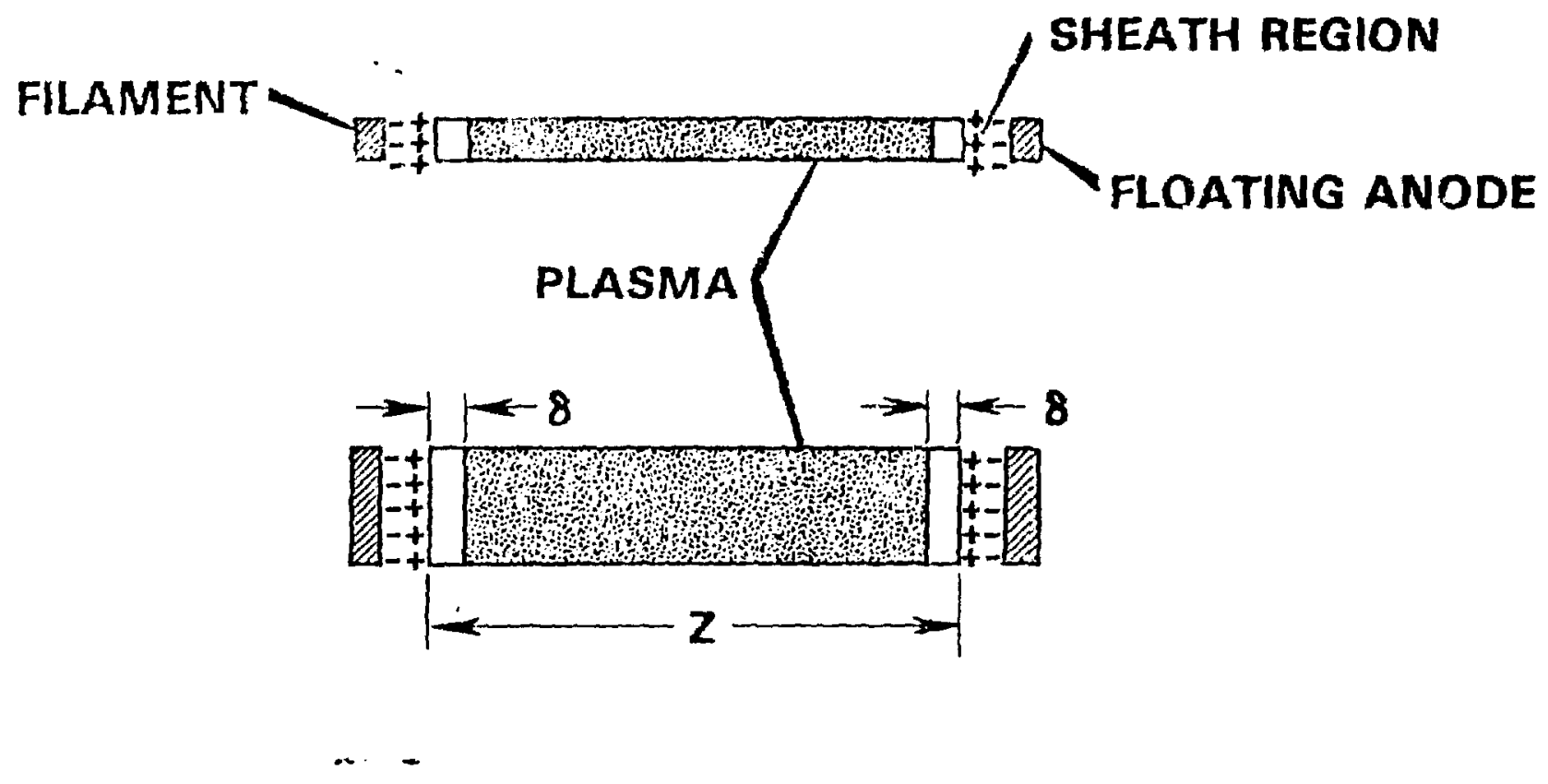

Fig. 5 


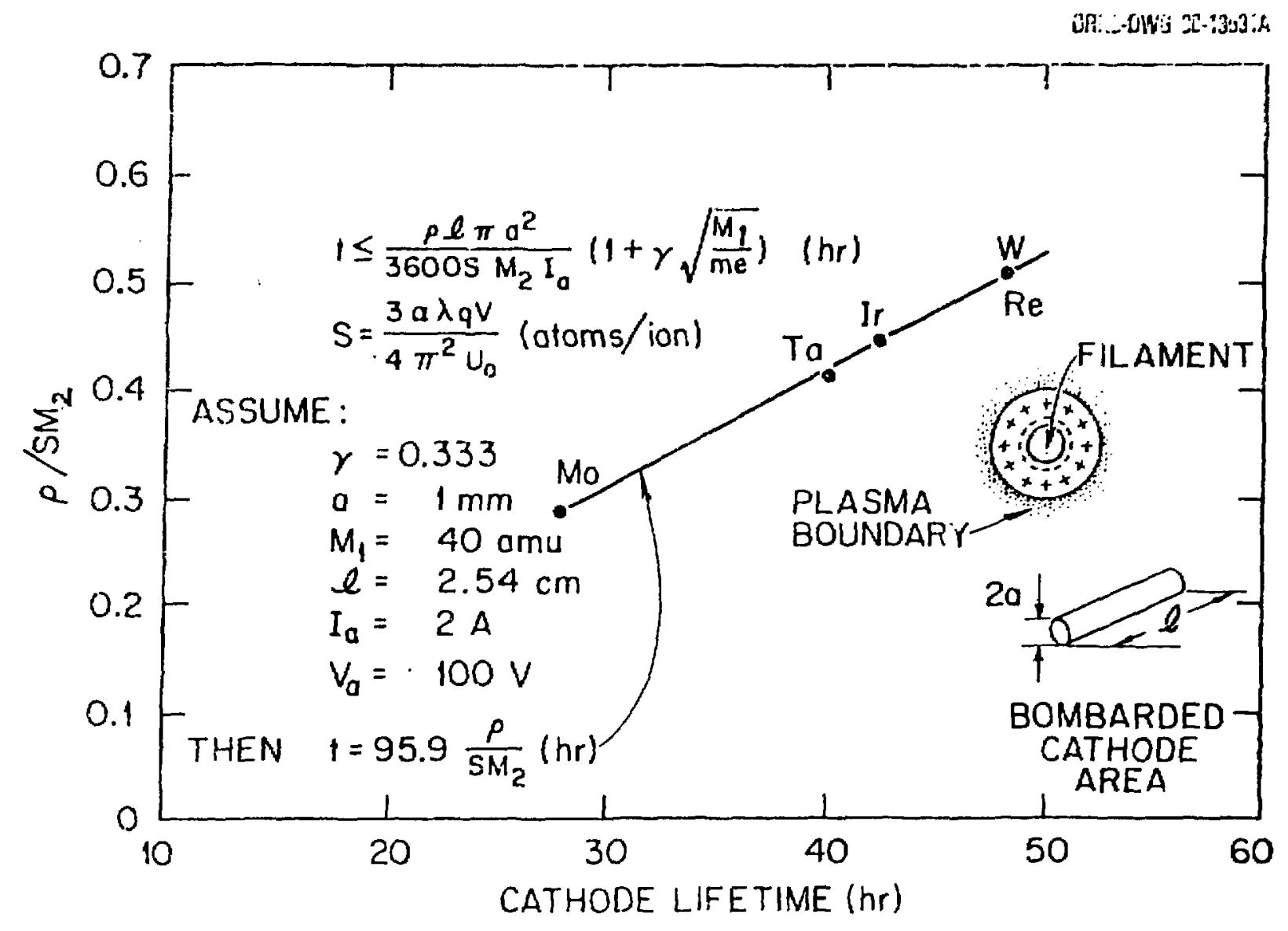




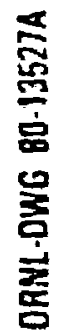
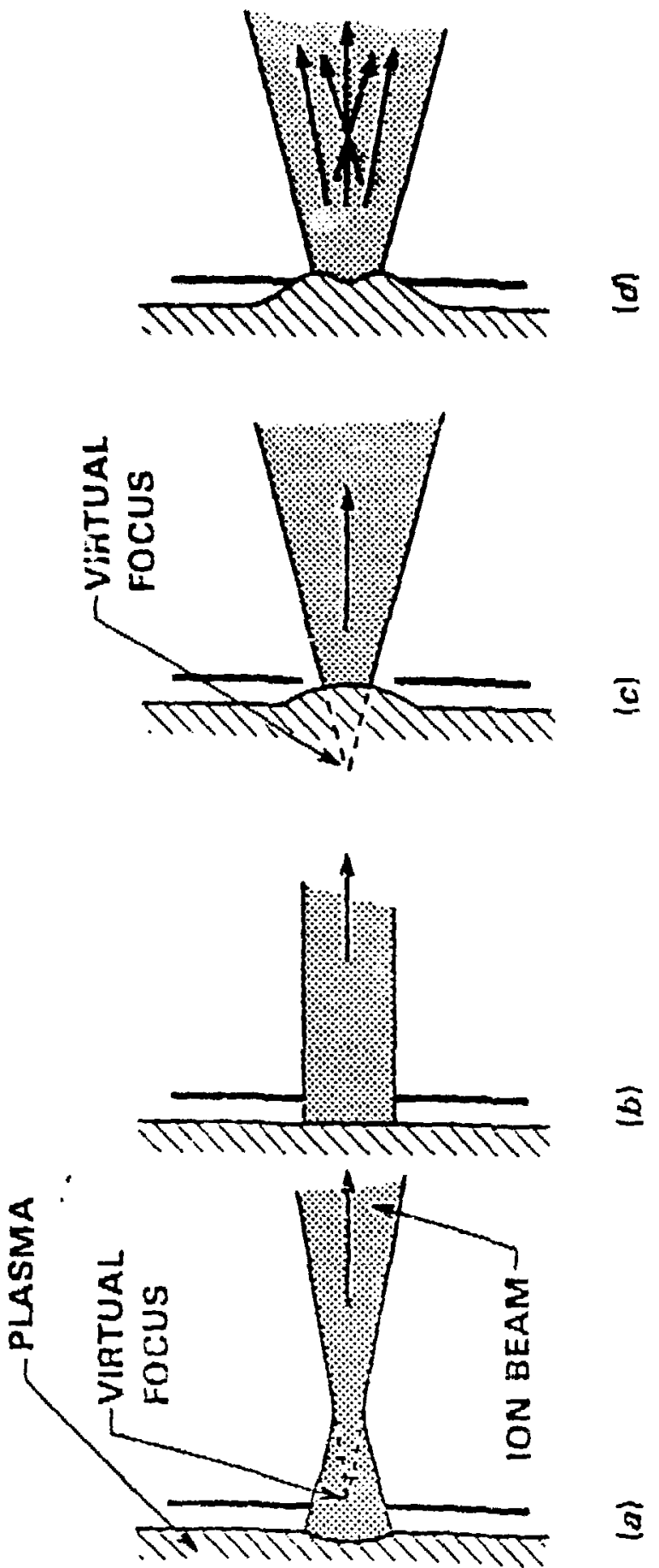
ORNL - DWG 8C-13.20

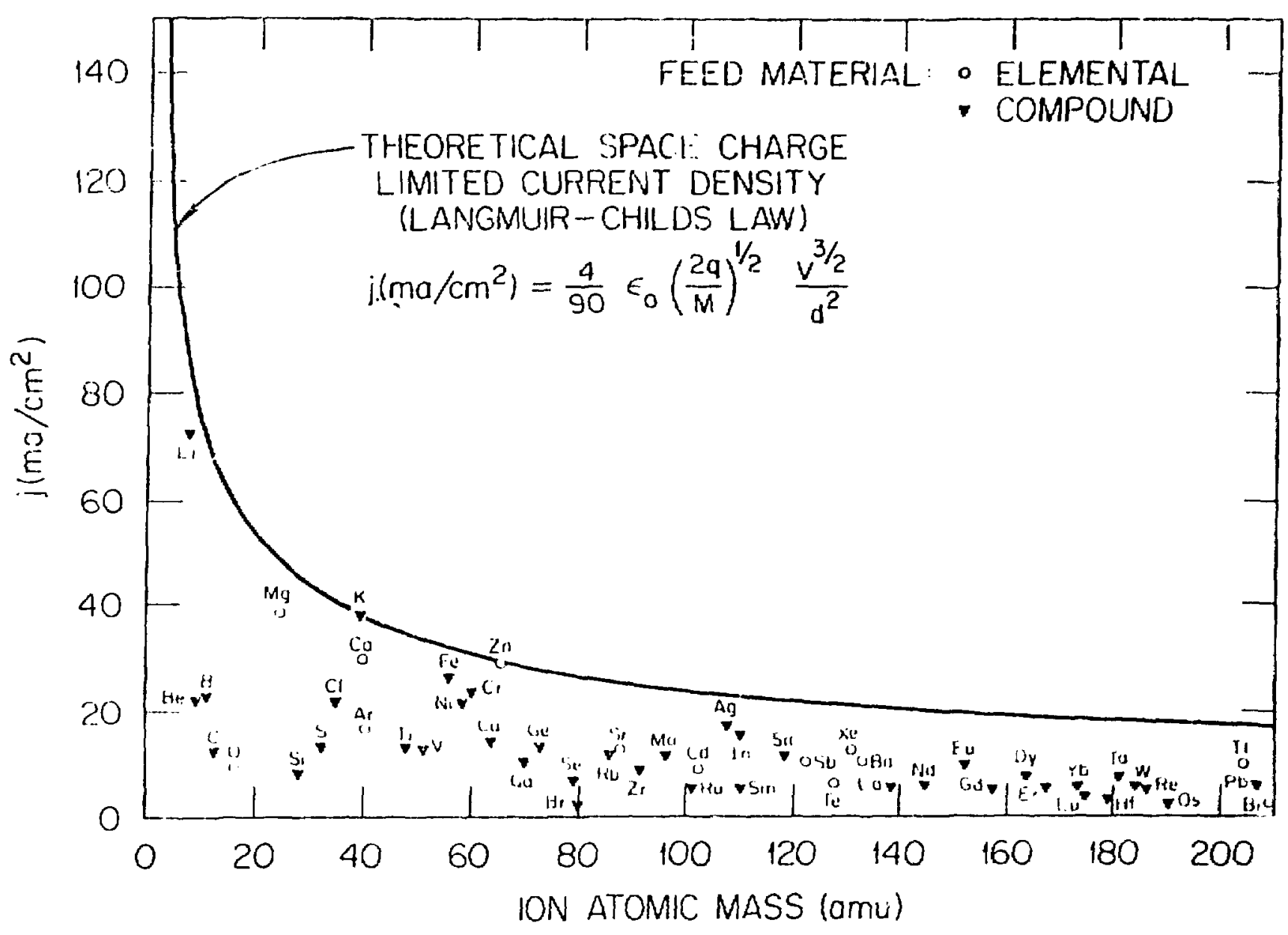

Fig. 8 
ORNL-DWG 80-13526A

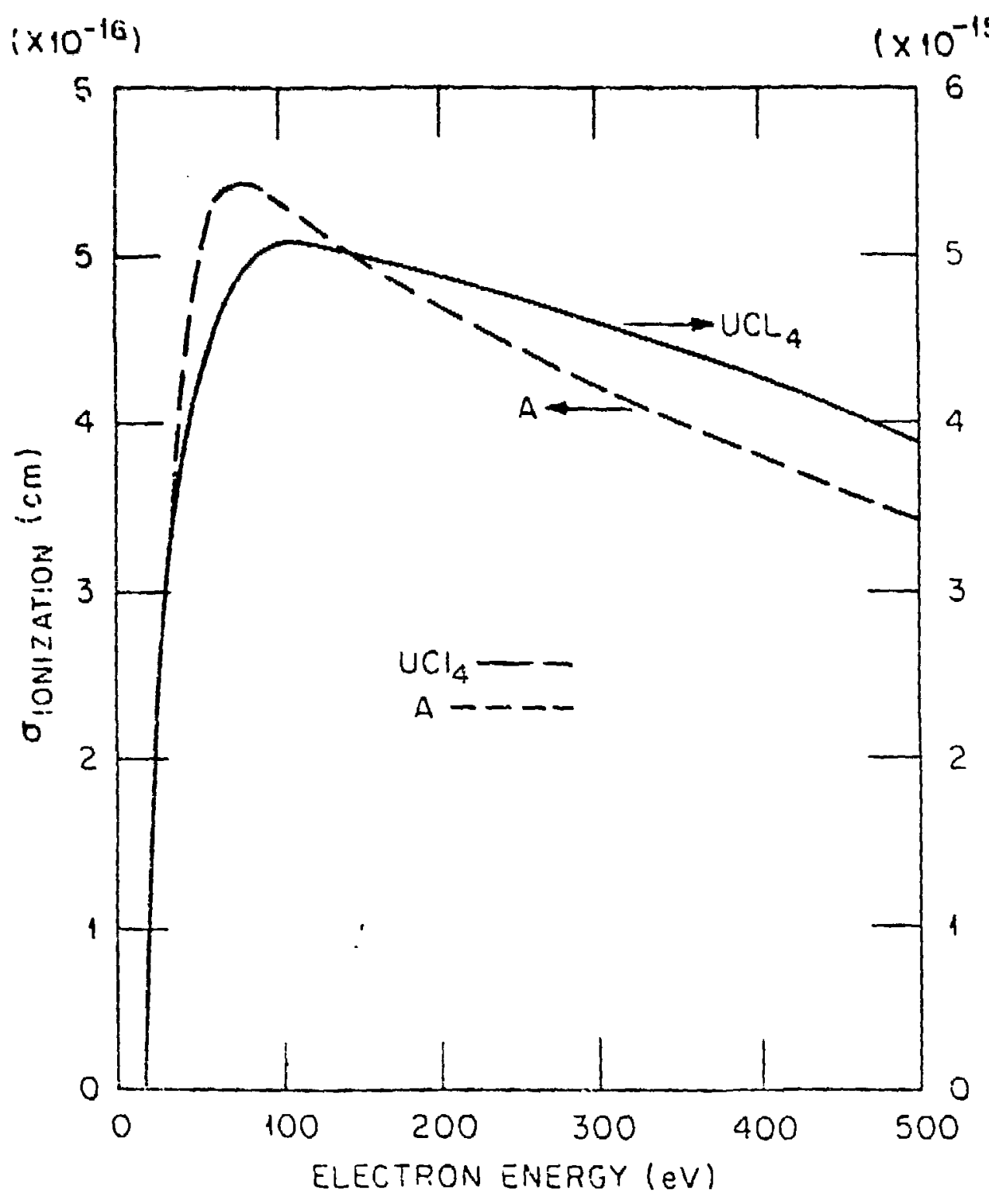

Fig. 9 
OHNL-DWG 80-13529A

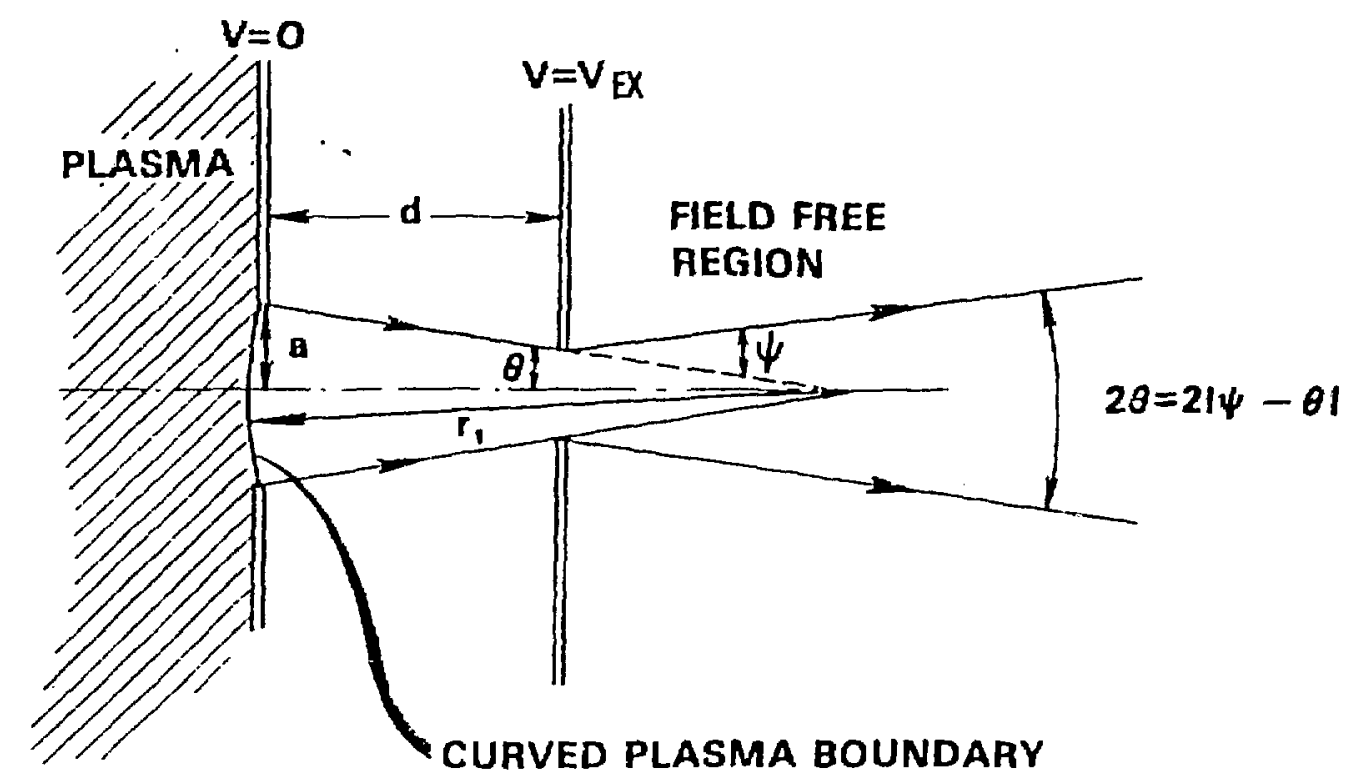


ORNL-DWG 80-135200A

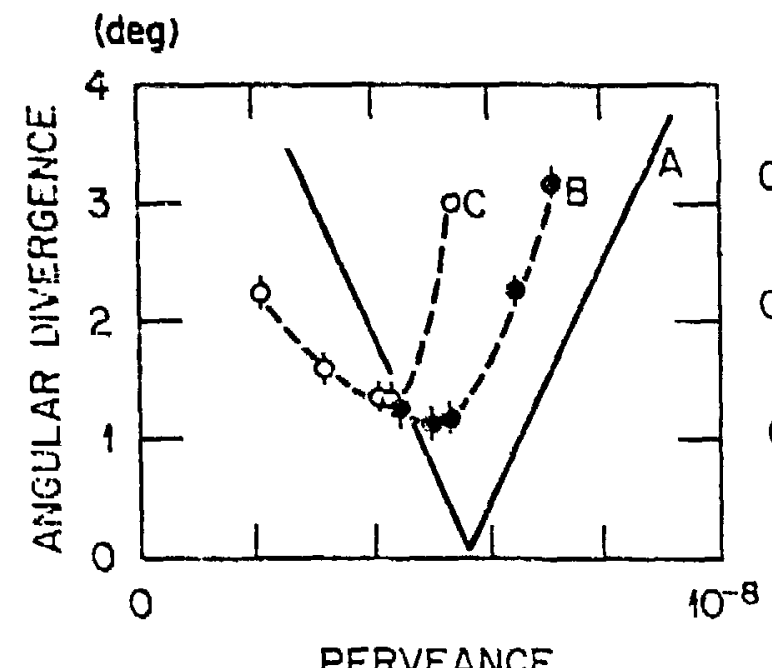

COUPLAND et al. (1972) (rad)

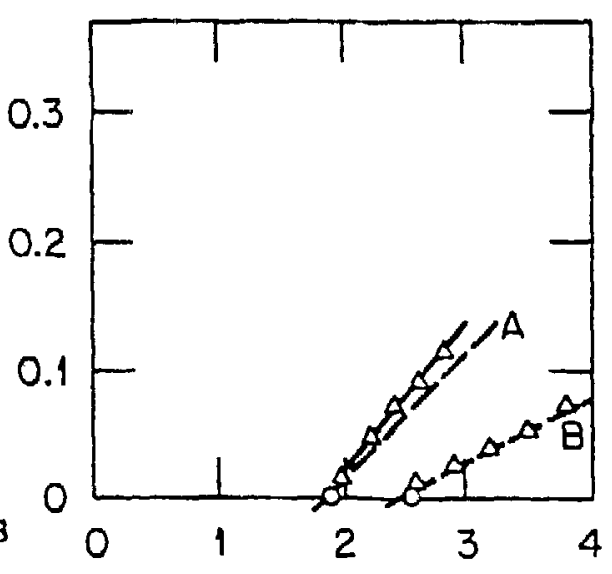

d, EXTRACTION GAP (cm) CHEVET-BERNAS (1967)

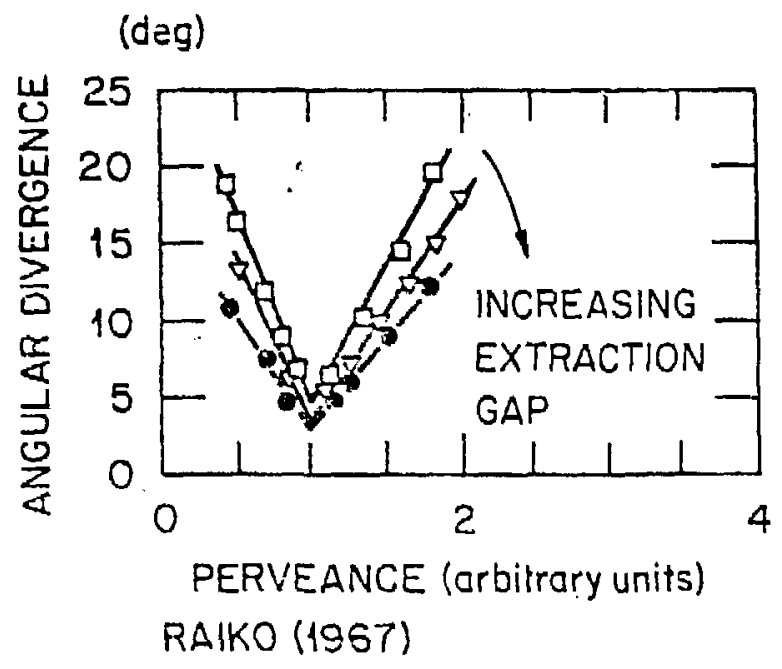

Fig. 11 
ORNL-DWG B0-13523A

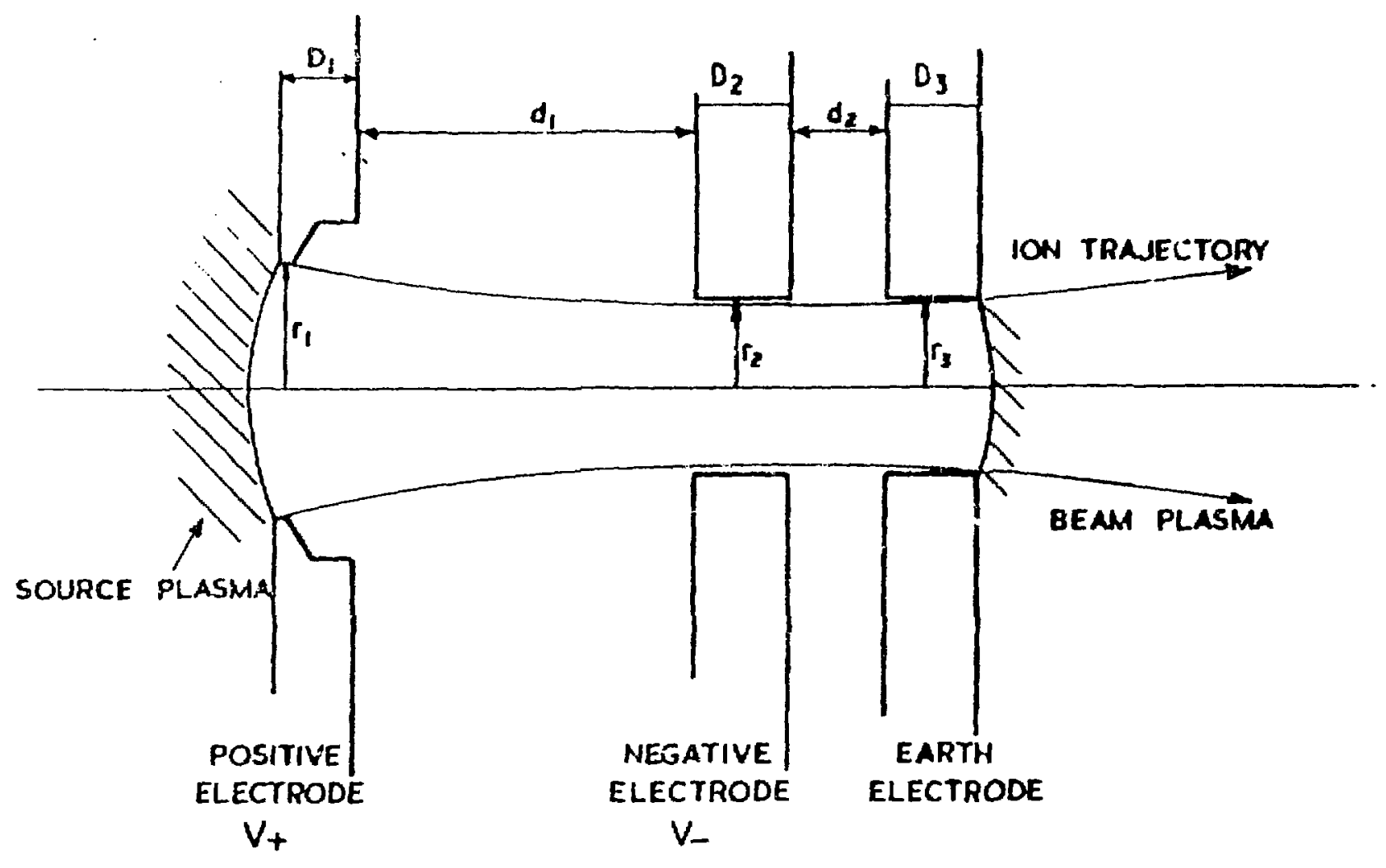


ORNL-DWG 79-2774 FED

CYL: j $=0.21$

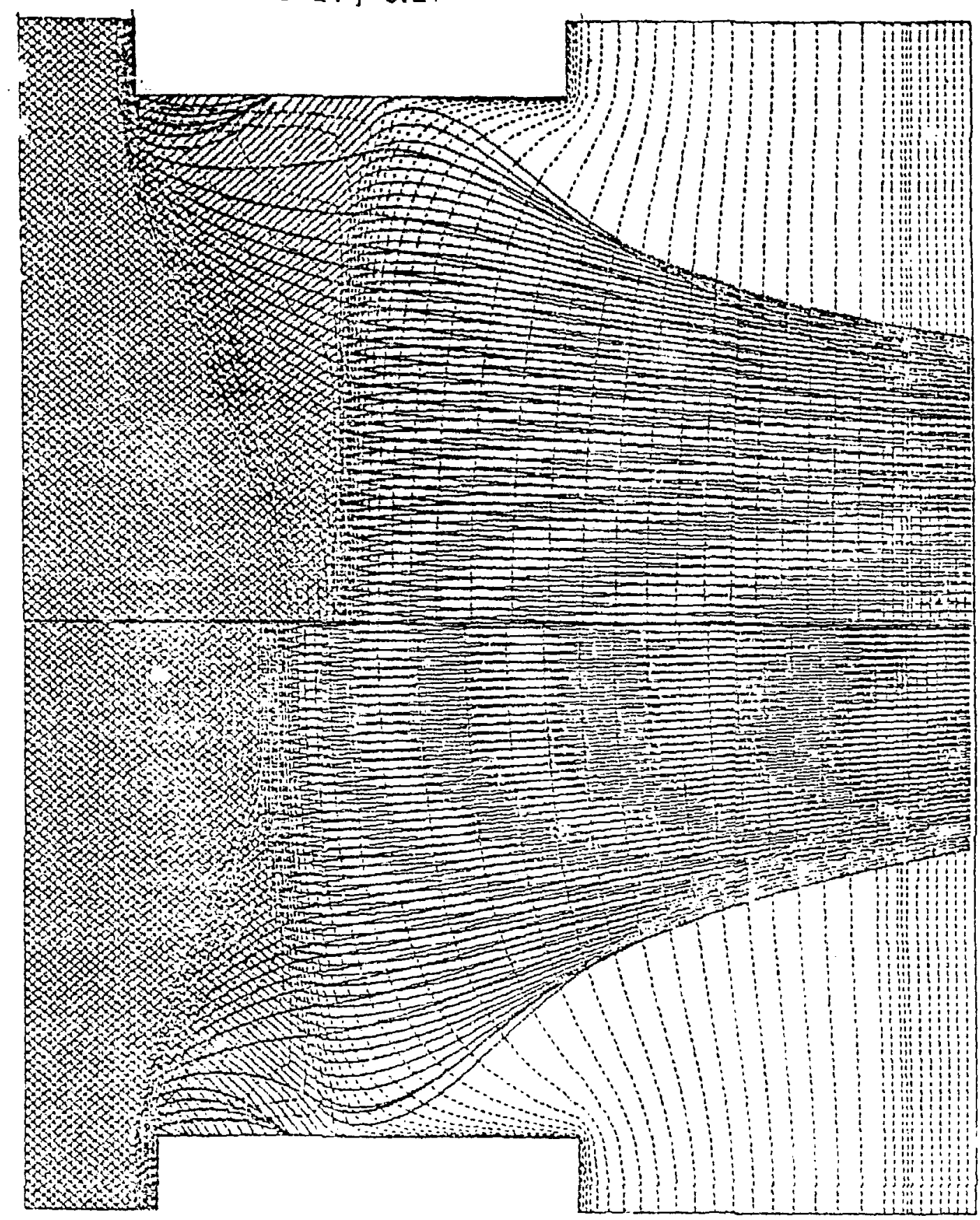

SLOT: $j=0.15$ 

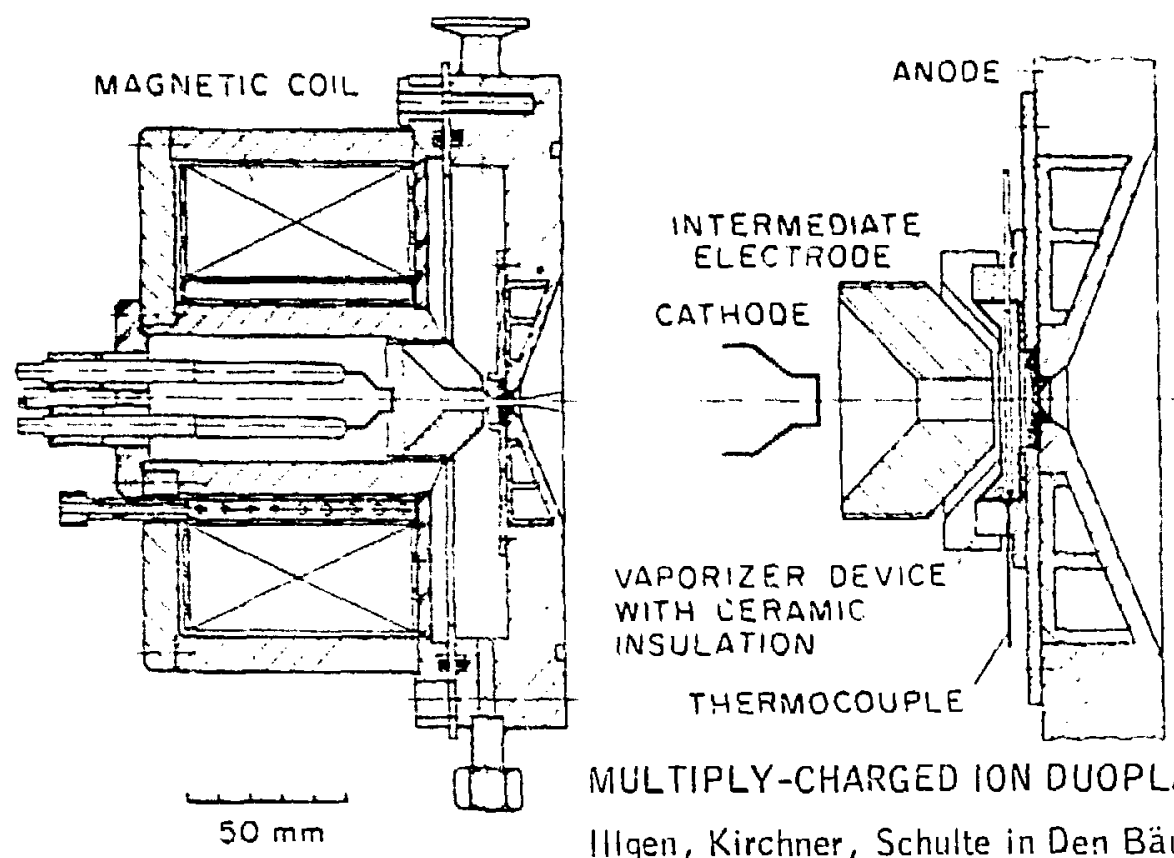

MULTIPLY-CHARGED ION DUOPLASMATRON Illgen, Kirchner, Schulte in Den Bäumen 1971

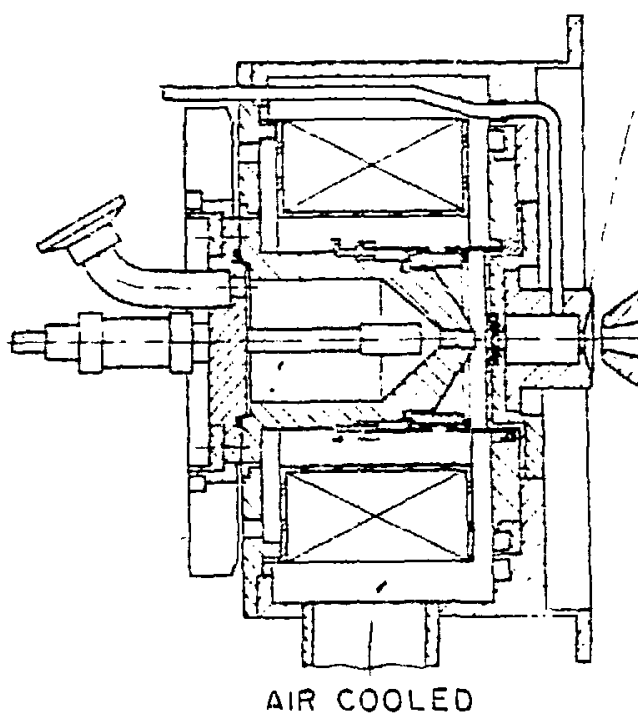

PLASMA EXPANSION CUP WITH GAS FEEC

PLASMA EXPANSION CUP WITH VAPORIZER DEVICE

EXTRACTOR

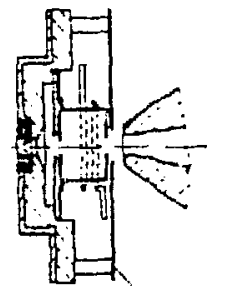

SCREEN

MASS SEPARATOR DUOPLASMATRON Wasic, Sautter, Warnecke 1969 
ORNL-DWG 74-10256

1. CHARGE INSERTION AND REMOUVAL CHAMBER

2. ISOLAHION VAI.VE

3. $\mathrm{CCI}_{4}$ INLET TUBE

4. SUPPORT GAS INLET TUBE

5. CHARGE MATERIAL CONTAINER

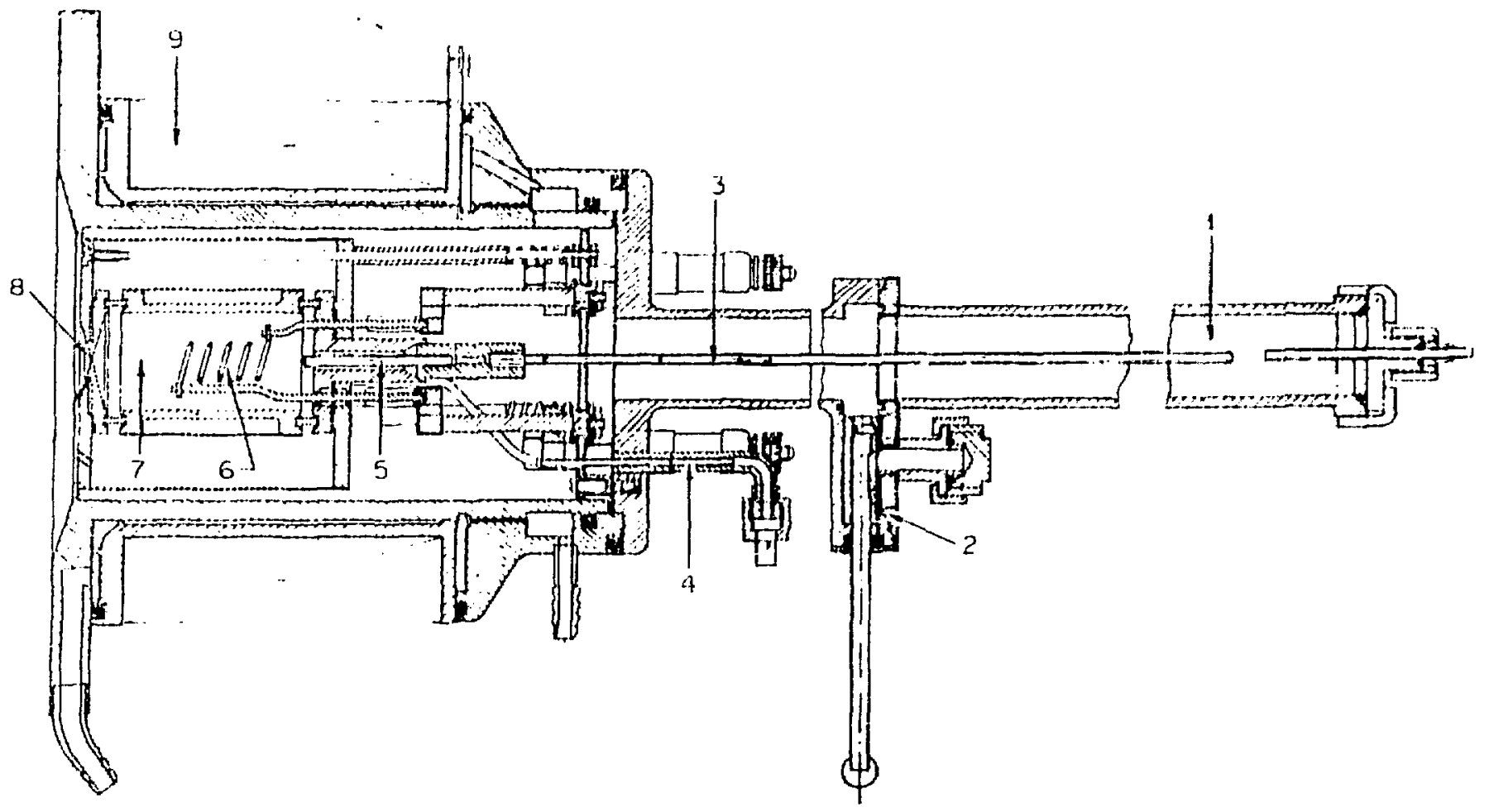

6. CATHODE (FILAMENT)

7. $A N O D E$

3. EXTRACTION APERTURE

9. MAGNET 

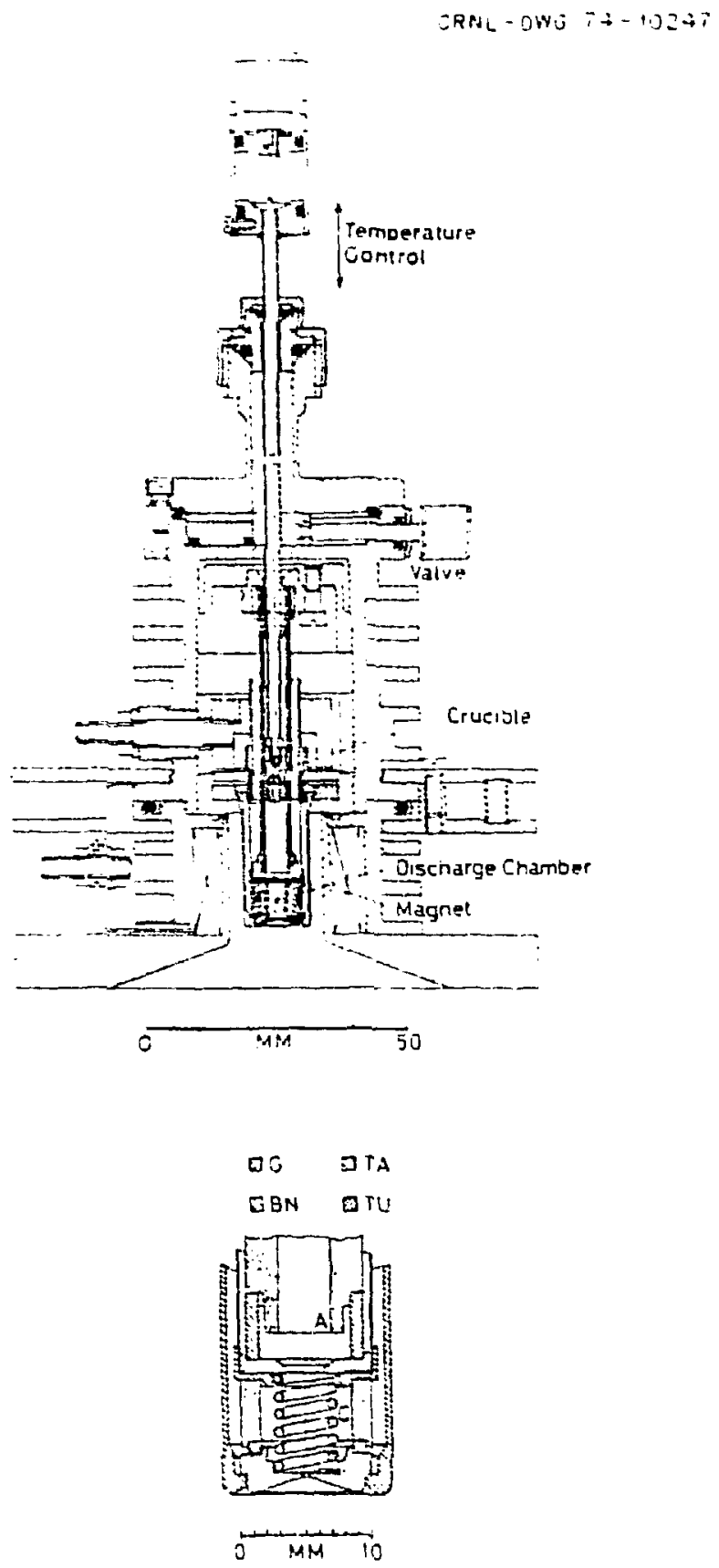

The Discherge Cnomoar a, Anode; C, Cothoge; i, aruorite; BN, Boron Nitride; TA, Tantalum; TU, Tungeten. Hollow Carhode Positue Ion Source (Sidenius).

Fig. 16 


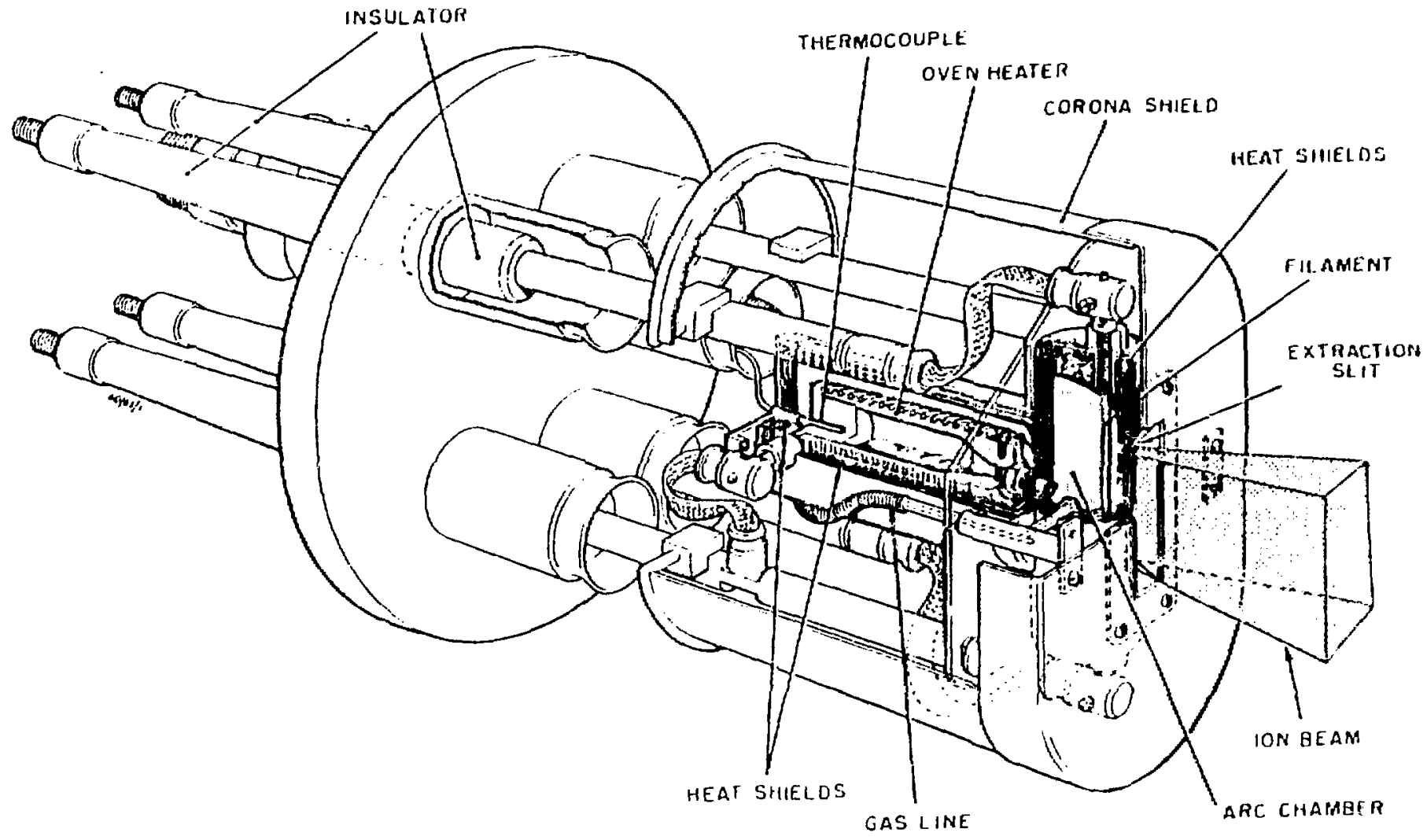


1 CHAFGE INSERTION ROD

2 ISOLATION CHAMBER

ISOLATION VALVE

POSITIVE ELECTRODE

GROUNOED ELECTRODE

ION GEAM

WEGR.TIVE ELECTRODE

aRC Chamuer

OVEN HEAILR

10 CHAHGE Conitainer

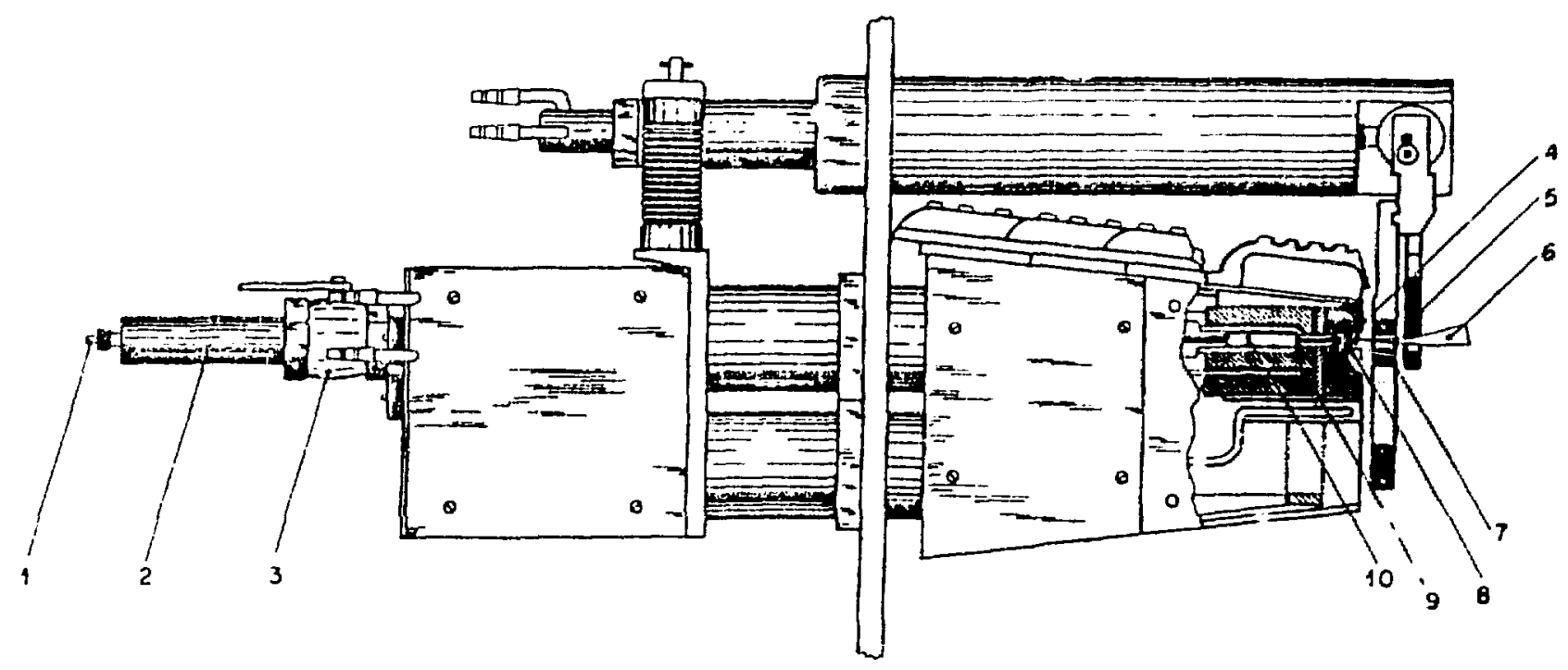

Fig. 18 


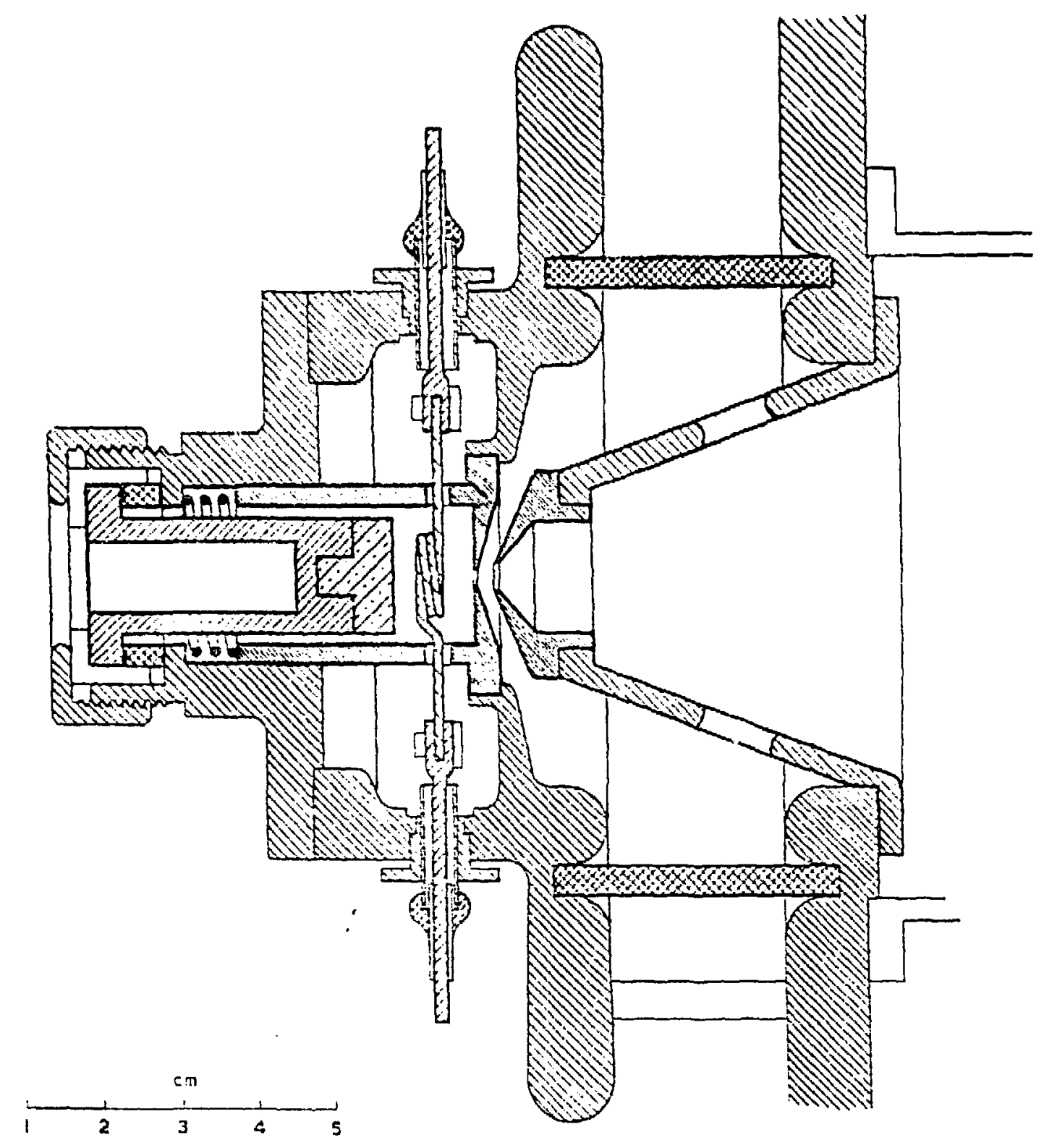




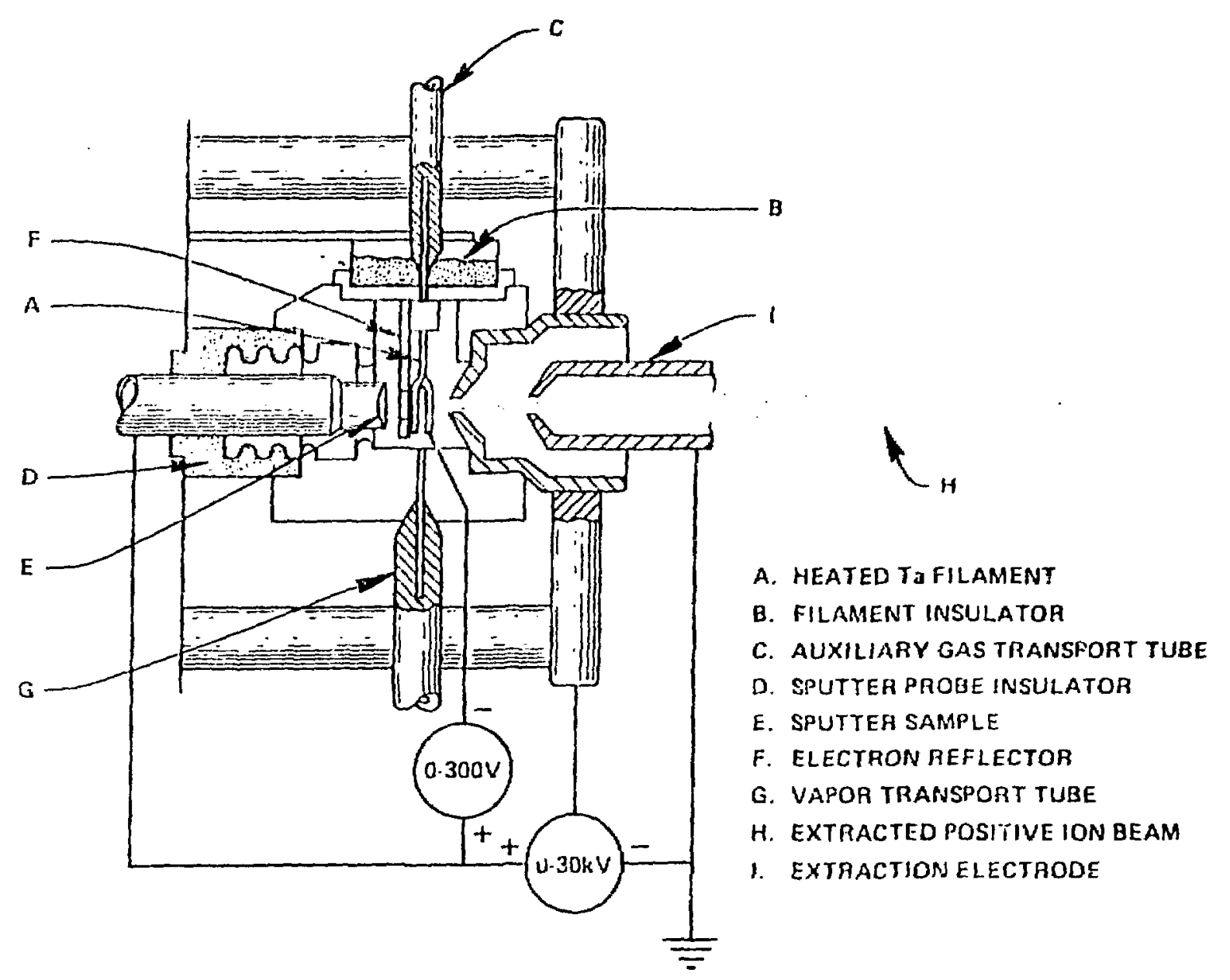


ORNL-DWG 74-10249
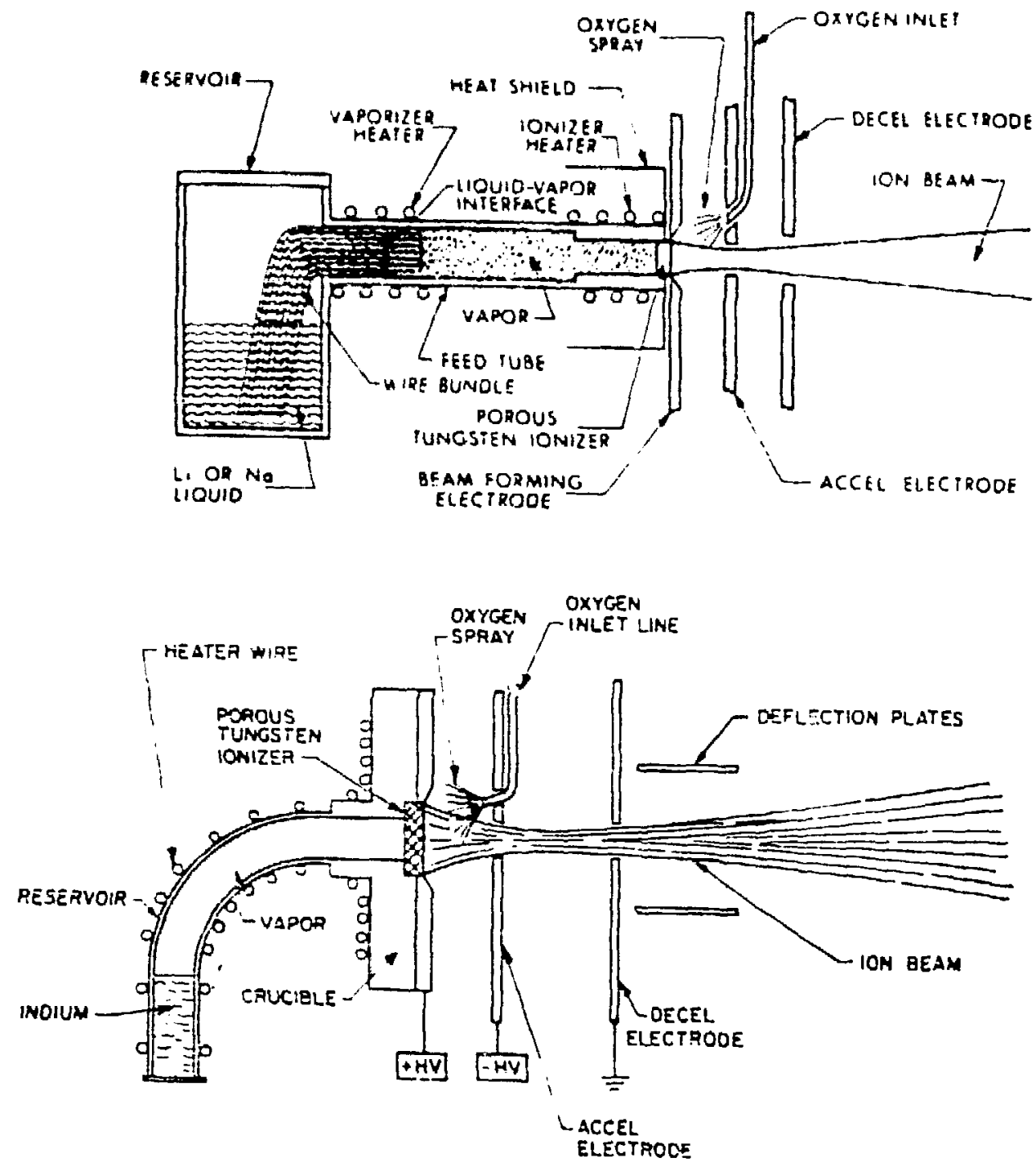

Fig. 21 


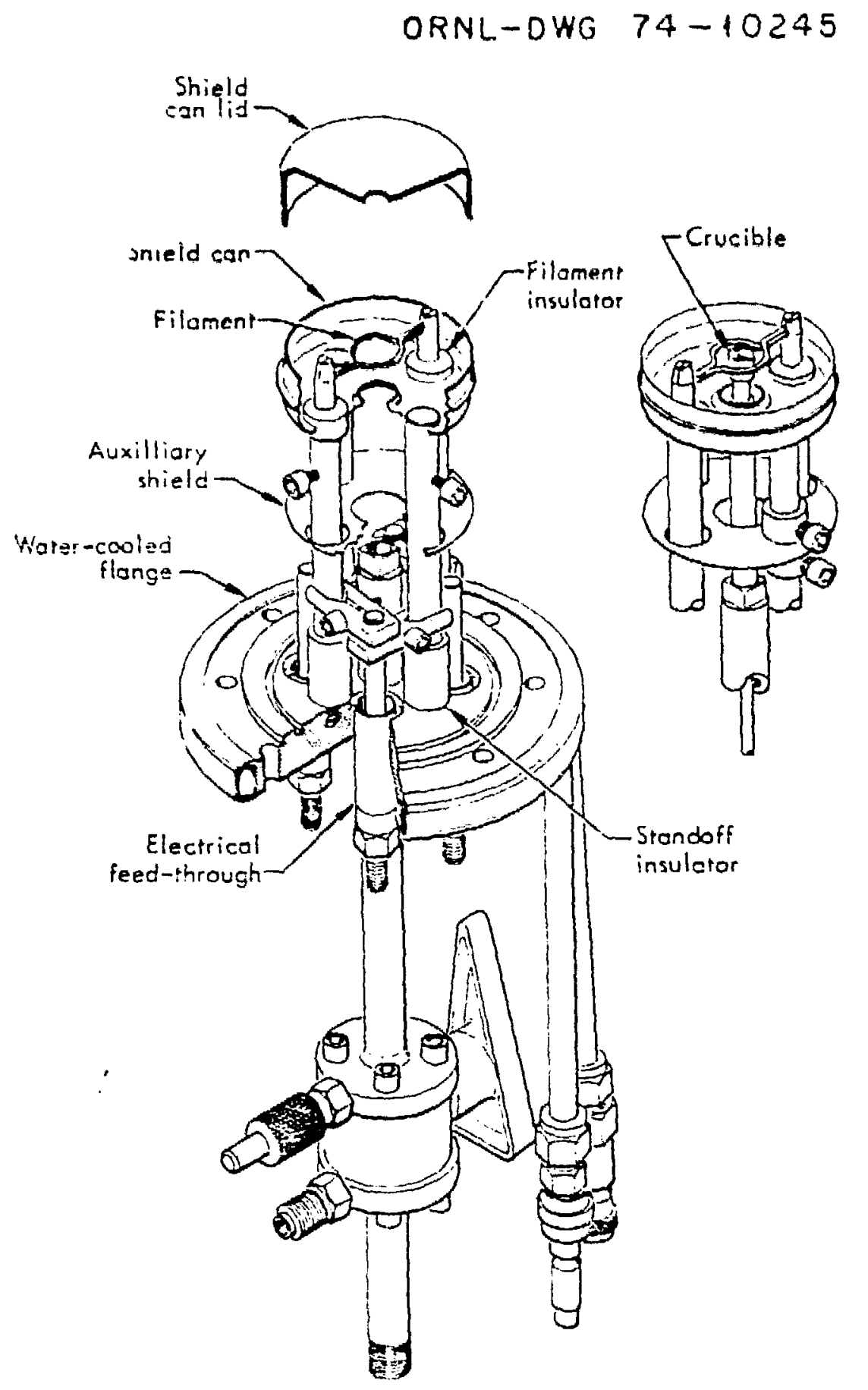

Fig. 22 


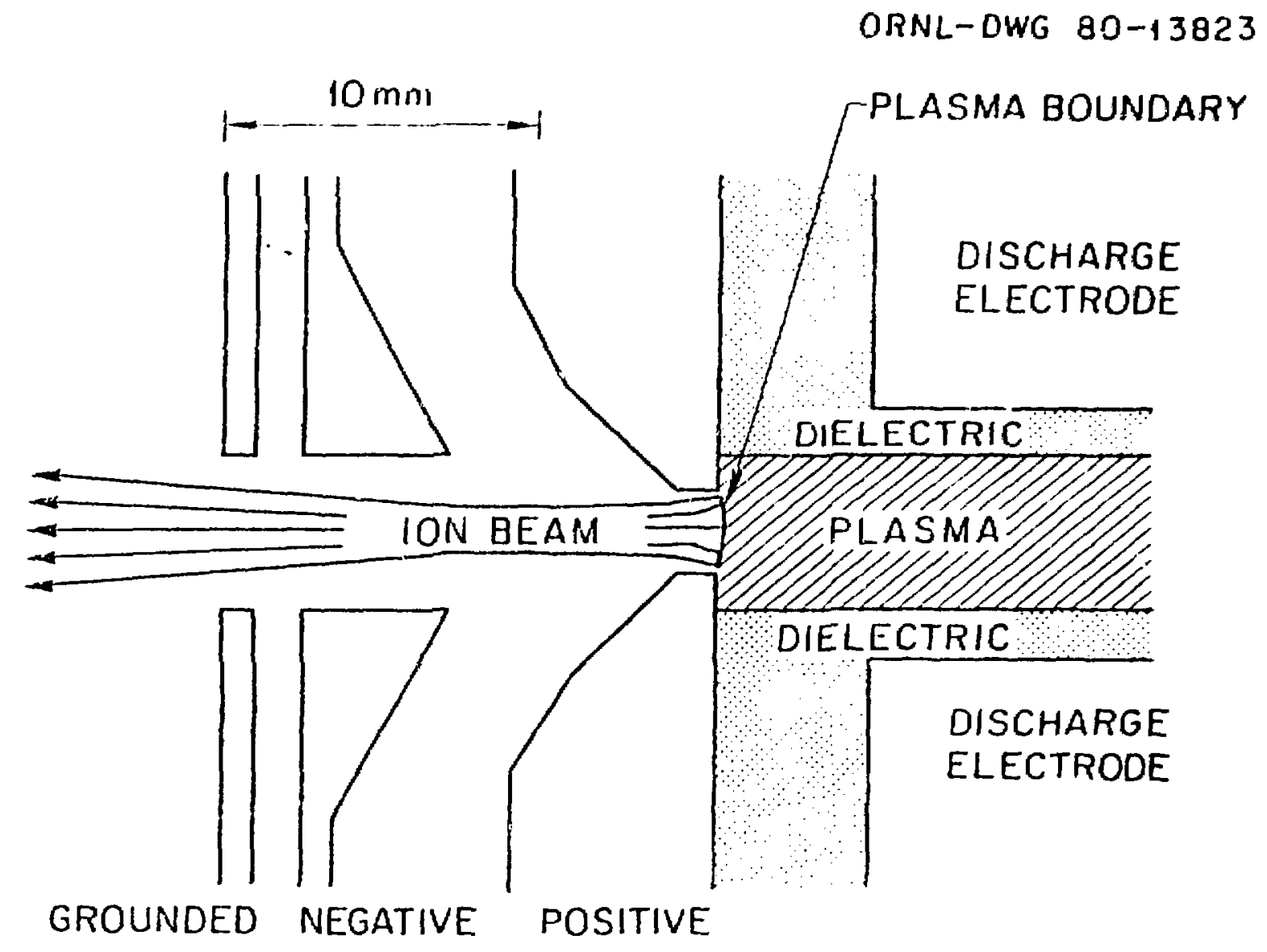

Fig. 23 